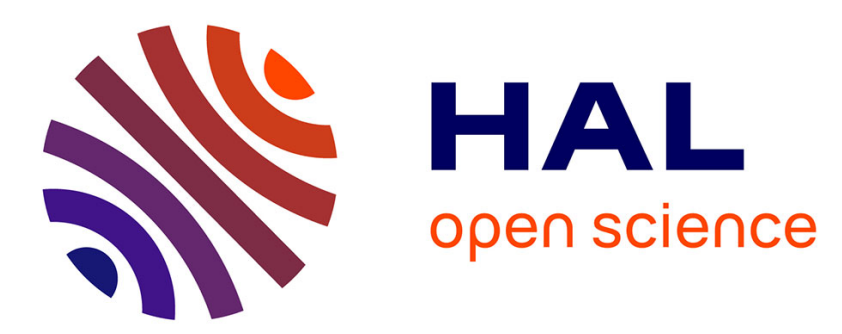

\title{
Experimental investigation of a confined flat two-phase thermosyphon for electronics cooling
}

\author{
Marine Narcy, Stéphane Lips, Valérie Sartre
}

\section{To cite this version:}

Marine Narcy, Stéphane Lips, Valérie Sartre. Experimental investigation of a confined flat twophase thermosyphon for electronics cooling. Experimental Thermal and Fluid Science, 2018, 10.1016/j.expthermflusci.2018.01.018 . hal-01735891

\section{HAL Id: hal-01735891 \\ https://hal.science/hal-01735891}

Submitted on 16 Mar 2018

HAL is a multi-disciplinary open access archive for the deposit and dissemination of scientific research documents, whether they are published or not. The documents may come from teaching and research institutions in France or abroad, or from public or private research centers.
L'archive ouverte pluridisciplinaire HAL, est destinée au dépôt et à la diffusion de documents scientifiques de niveau recherche, publiés ou non, émanant des établissements d'enseignement et de recherche français ou étrangers, des laboratoires publics ou privés. 


\title{
EXPERIMENTAL INVESTIGATION OF A CONFINED FLAT TWO-PHASE THERMOSYPHON FOR ELECTRONICS COOLING
}

\author{
Marine Narcy, Stéphane Lips*, Valérie Sartre \\ Univ Ly on, CNRS, INSA-Ly on, CETHIL UMR5008, F-69621, Villeurbanne, France \\ *stephane.lips@insa-lyon.fr
}

\begin{abstract}
A novel type of two-phase heat spreader based on a flat confined thermosyphon is proposed for electronics cooling applications. Two wickless flat copper-water heat pipes with an inner thickness of $3 \mathrm{~mm}$ were experimentally investigated for two-phase flow visualizations and characterization of thermal performance. The effects of heat input, filling ratio, inclination, and saturation temperature were studied. Experimental results show that the confinement of the fluid inside the heat spreader induces confined boiling phenomenon with a strong coupling between condensation and boiling mechanisms. They also highlight an enhancement of heat transfer and interesting performance such as high heat transfer capability (tested up to $10 \mathrm{~W} / \mathrm{cm}^{2}$ with a corresponding thermal resistance around $0.07 \mathrm{~K} / \mathrm{W}$ at an optimum filling ratio), low sensitivity to inclination and higher degree of freedom on heat sources location compared to a classical thermosyphon.
\end{abstract}

Keywords: heat pipe, two-phase heat spreader, thermosyphon, confined boiling

\section{Nomenclature}

\section{Roman symbols}

$\begin{array}{ll}A & {\left[\mathrm{~m}^{2}\right]} \\ B o & {[-]} \\ D & {[\mathrm{~m}]} \\ C p & {[\mathrm{~kJ} / \mathrm{K} / \mathrm{kg}]} \\ e & {[\mathrm{~m}]} \\ g & {\left[\mathrm{~m} / \mathrm{s}^{2}\right]} \\ h & {\left[\mathrm{~W} / \mathrm{K} / \mathrm{m}^{2}\right]} \\ h \text { fg } & {[\mathrm{J} / \mathrm{kg}]} \\ L & {[\mathrm{~m}]} \\ \dot{m} & {[\mathrm{~kg} / \mathrm{s}]} \\ P & {[\mathrm{~Pa}]} \\ P r & {[-]} \\ Q & {[\mathrm{~W}]} \\ q & {\left[\mathrm{~W} / \mathrm{m}^{2}\right]} \\ R & {[\mathrm{~K} / \mathrm{W}]} \\ R e & {[-]} \\ T & {\left[{ }^{\circ} \mathrm{C}\right]} \\ x & {[\mathrm{~m}]}\end{array}$

surface

Bond number

diameter

specific heat

heat spreader inner thickness

acceleration due to gravity

heat transfer coefficient

latent heat of vaporization

length

mass flow rate

pressure

Prandtl number

heat load

heat flux

thermal resistance

Reynolds number

temperature

heat spreaderaxis coordinate
Greek symbols

$\Delta$

$\lambda \quad[\mathrm{W} / \mathrm{m} / \mathrm{K}]$

$\left[\mathrm{Ns} / \mathrm{m}^{2}\right]$

$\left[\mathrm{m} / \mathrm{s}^{2}\right]$

$\left[\mathrm{kg} / \mathrm{m}^{3}\right]$

$[\mathrm{N} / \mathrm{m}]$

difference

thermal conductivity

dynamic viscosity

kinematic viscosity

density

surface tension

$\begin{array}{ll}\text { Subscripts } & \\ \text { atm } & \text { atmospheric } \\ \text { b } & \text { bubble departure } \\ \text { cap } & \text { capillary } \\ \text { cond } & \text { condensation } \\ \text { conduction } & \text { conduction } \\ \text { cool } & \text { cooling } \\ \text { crit } & \text { critical } \\ \text { evap } & \text { evaporation } \\ \text { exp } & \text { experimental } \\ \text { fl } & \text { film } \\ \text { i } & \text { inner }\end{array}$

$\begin{array}{ll}\text { in } & \text { inlet } \\ \text { max } & \text { maximal } \\ \text { meas } & \text { measured } \\ \text { min } & \text { minimal } \\ \text { out } & \text { outlet } \\ \varphi & \text { phase change } \\ \text { sat } & \text { saturation } \\ \text { theo } & \text { theoretical } \\ \text { w } & \text { wall }\end{array}$




\section{INTRODUCTION}

Due to perpetual advances in electronic engineering with the pursuing of higher performance and device miniaturization, thermal management of electronic components requires to deal with continuously increasing heat fluxes and local temperatures: between the years 2000 and 2010, the associated heat fluxes were multiplied by more than ten, eventually reaching $120-150 \mathrm{~W} / \mathrm{cm}^{2}$ for some applications (Faghri, 2014). Since the lifetime and reliability of electronic components is sensitive to their operating temperature, these increasing demands on heat dissipation create a need for efficient devices with high heat transfer and heat spreading capabilities.

Heat pipes (Reay et al, 2013) and micro heat pipes (Sobhan et al, 2007) were first considered as an adequate solution for electronics cooling with their high effective thermal conductivity, passiveness, and performance for temperature control. However, today's requirements highlight their limitations in terms of heat transfer and temperature uniformity (Faghri, 2014). Two-phase thermosyphons, also known as wickless or gravity-assisted heat pipes, therefore emerged as an alternative for small-scale applications with better thermal performance (Jafari et al, 2016).

The main physical mechanisms taking place in a classical two-phase closed thermosyphon (TPCT) are illustrated in Figure 1a. A heat flux is supplied to the working fluid through the evaporator wall in the lower section of the device, causing the liquid contained in the cavity to start to evaporate. Vapor flows upwards in the pipe up to the condenser region where it condenses on the inner wall, forming a liquid film that is returned back to the evaporator by gravity.

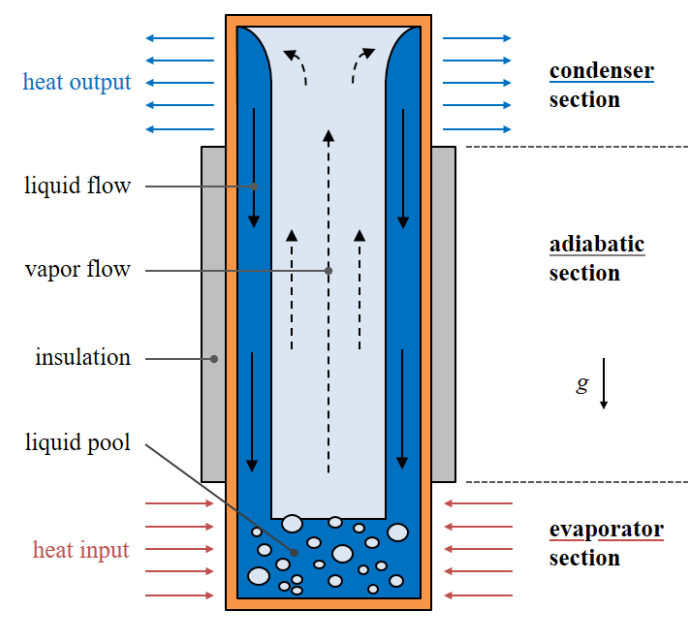

(a) operating principle

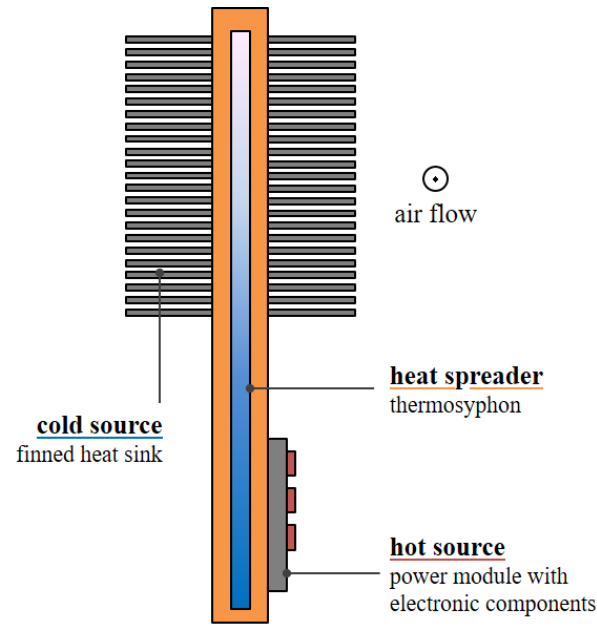

(b) example of application as heat spreader for electronics cooling

Figure 1. Classical thermosyphon: operating principle and application.

Because of the significant latent heat of vaporization as sociated to phase change, a large amount of heat can be transferred from the evaporator section to the condensersection with a very small relative temperature difference. If the condensation area is larger than the evaporation area, the device also acts as a heat spreader, as illustrated in Figure $1 \mathrm{~b}$ where the heat is transferred from a power module to a larger heat sink consisting of fins.

TPCTs generally do not include wick structures, unlike conventional heat pipes: since gravity is the major driving force for condensate return, they exhibit neither a large flow resistance nor a low boiling limit inside the wick, which is of great interest for high heat flux applications where conventional heat pipes show limitations.

In addition to their high heat transfer and spreading capability, TPCTs have other interesting features for electronics cooling in challenging environments such as aeronautical environments: their geometry can easily be adapted to fit power modules or flat electronic components, or to meet space constraints; with the absence of wick, they are also simpler and cheaper to manufacture and do not raise the issue of frozen start-up in capillary structure.

However, TPCTs are constrained by otheroperating parameters since their thermohydraulic behavior is strongly affected by the heat input, the filling ratio, the working fluid and the device design.

In particular, TPCTs are very constrained regarding the heat source location: the evaporator section has to be at the same level than the liquid pool to avoid dry-outs of the liquid film, which requires a vertical positioning of the heat source below the condenser section, at the very bottom of the device (Jafari et al, 2016). TPCTs are also characterized by a high sensitivity to inclination since gravity ensures the condensate return to the evaporator. The influence of the inclination angle on the thermal performance of classical thermosyphons was studied by various authors (Noie et al, 2007; Ong et al, 2014; Zhang et al, 2014, Hu et al, 2016...) with different quantitative conclusions depending on the working fluid and heat pipe geometry. Nevertheless, consistent trends were observed with significant changes in the thermal resistance according to 
inclination angle and optimum conditions in intermediate configurations between vertical and horizontal positions, which can be a problem in the case of applications where the inclination is expected to change.

These drawbacks may nonetheless be limited by introducing an additional geometrical parameter, the confinement of the fluid inside the heat pipe. Indeed, the inner diameter (for cylindrical or an nular thermosyphons) or the inner thickness (for flat thermosyphons) plays an important role in the balance of forces that rules boiling phenomena in the device. Decreasing this dimension to small scales promotes surface tension forces over buoyancy forces, which could limit the influence of the inclination angle through gravity forces, for instance.

The condition for a TPCT to be considered confined can be related to a low Bond number Bo indicating that the forces due to surface tension are not negligible (Terdtoon et al, 1999; Franco and Filippeshi, 2013) or to characteristic length comparable to expected bubble departure diameter (Jouhara and Robinson, 2010) or capillary length of the working fluid. Moreover, confined boiling phenomena are often as sociated with an enhancement of heat transfer in pool boiling. Bonjour and Lallemand (1998) experimentally studied boiling in a confined rectangular vertical channel and provided flow pattems maps based on $B o$ number including flow regimes corresponding to he at transfer enhancement. Similar conclusions were reached in cylindrical confined spaces by Rops et al (2009). They showed that the heat transfer enhancement for nucleate boiling regimes is induced by an increase in the vapor velocity and the liquid entrainment rate through the confinement of the channel that deforms the vapor bubbles. A confined TPCT may therefore exhibit better thermal performance with reduced limitations.

On the basis of these considerations, the present study aims at proposing a novel type of two-phase heat spreader for electronics cooling in constrained configurations such as in aeronautical environments, by combining features of two-phase thermosyphons and confined two-phase systems. Considering the requirements in terms of thermal management of electronic components, and the advantages and drawbacks of TPCTs, a suitable heat spreader would consist in a flat confined two-phase thermosyphon.

However, compared to classical thermosyphons mostly used in solar or deicing systems, the consequent changes in both dimensions and geometry (especially the changing from cylindrical to flat geometry) are going to significantly affect the two-phase flow and thermal performance of the spreader. The introduction of the confinement is also expect ed to induce major changes in the flow patterns and thermal resistance due to the strong coupling between boiling and condensation processes (Zhang et al, 2013). Visualizations of flow patterns are therefore needed to characterize the complicated twophase behavior and correlate it with thermal performance. Experiments with direct visualizations are complex and then rarely performed. Some observations were realized in relatively large transparent cylindrical TPCTs by Li et al (2016), Smith et al (2016) or using electrical capacitance tomography (Liu et al, 2007). Existing results from flow visualizations are often partial and the conditions in which they were obtained are most of the time not clearly indicated.

Thus, an extensive experimental investigation of this new heat spreader including flow patterns descriptions is necessary to understand the underlying thermohydraulic phenomena and propose adequate designs to meet challenging specifications such as high heat fluxes, compactness, changing inclination or large degree of freedom on the heat source location.

In order to achieve this goal, a flat confined TPCT with adapting front panel was designed and built, as detailed in Section 2. This heat spreader relies on confined boiling phenomena to ensure proper operation in various constrained configurations and provided flow visualizations and assessments of thermal performance that are discussed in Section 3 . Results also include comparisons with empirical correlations that are available in the literature for heat transfer coefficients.

\section{EXPERIMENTAL SET-UP AND DATA REDUCTION}

\subsection{Experimental set-up}

The experimental set-up built to study the heat spreader is presented in Figure 2. The device is connected to the graduated filling system and mounted on an inclinable support that enables to set an inclination angle $\theta$ between $0^{\circ}$ and $180^{\circ}$ (horizontal position with evaporator and condenser on top, and horizontal position with evaporator and condenseron the bottom, respectively, with $\theta=90^{\circ}$ corresponding to the vertical configuration of the schematics). 


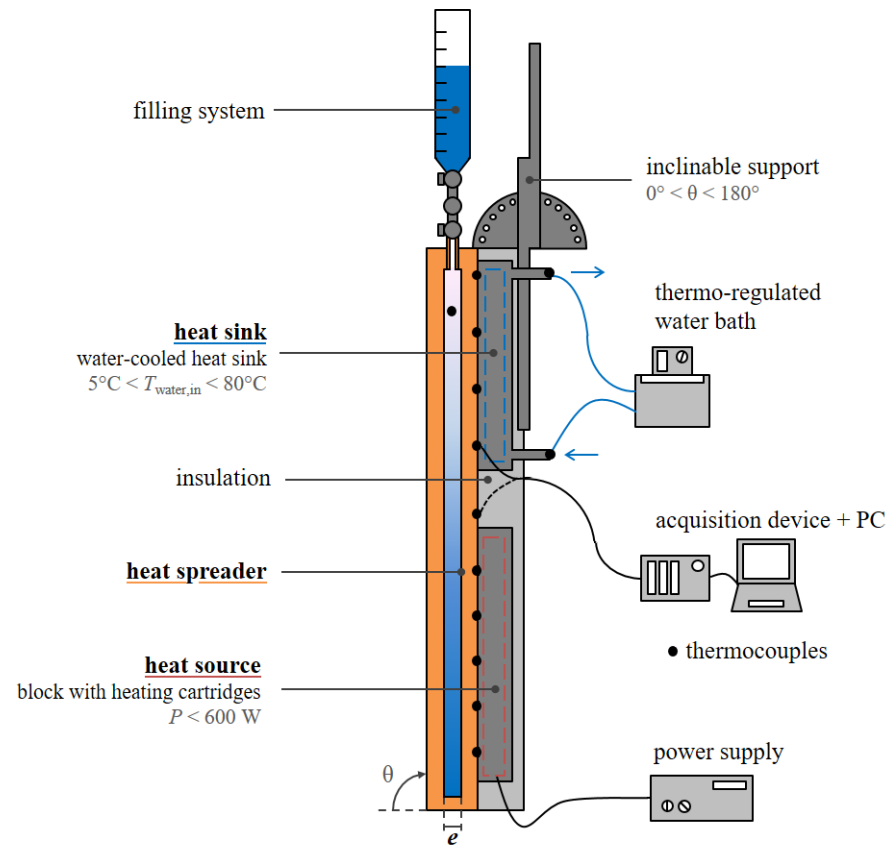

(a) cross-section schematics

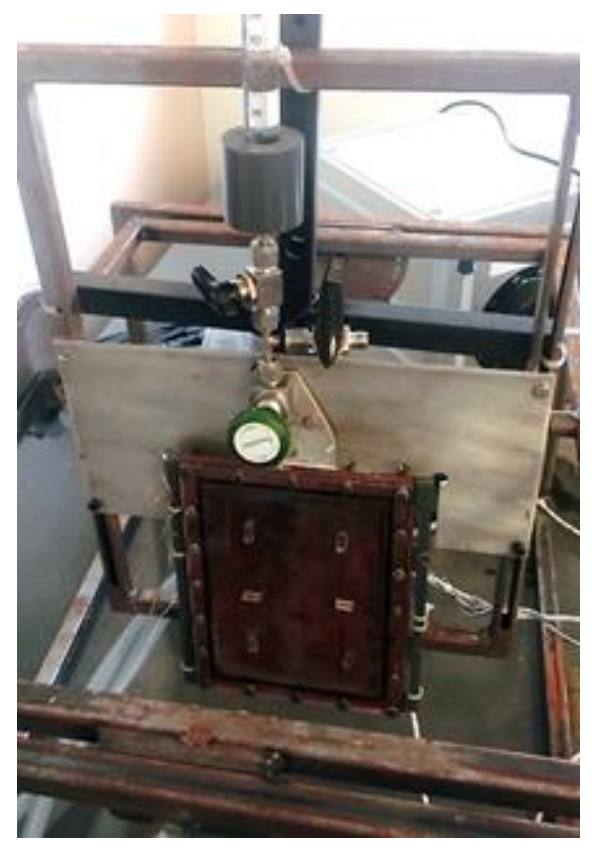

(b) front picture with the transparent heat spreader

Figure 2. Experimental set-up, zoom on the test bench with the heat spreader.

The heat spreader itself consists in a copper sealed flat container where vacuum is made and that is then filled with a variable amount of water, in the same way as a thermosyphon. Water was chosen as the working fluid because of its compliance with aeronautical specifications, its performance for the targeted application and its compatibility with copper.

The back panel of the heat spreader is a $3 \mathrm{~mm}$ thick copper plate of dimensions $12 \mathrm{~cm} \times 18 \mathrm{~cm}$ with inner vertical superficial $200 \mu \mathrm{m}$ wide grooves that are used for heat transfer enhancement and not as a capillary structure. The front panel is $2.5 \mathrm{~mm}$ thick and declined in two versions for the device to adapt to two different functions: it is either in copper (for a full copper spreader, as in Figure $3 b$ ) to easily characterize thermal performance during parametric runs or in polycarbonate (transparent spreader, as in Figure 3a) to provide flow visualizations. In both cases, the thickness of the inn er cavity (denoted $e$ in Figure 2) is $3 \mathrm{~mm}$, i.e. close to the capillary length of water, which ensures the system confinement and induces confined boiling phenomena.

The sealing of the heat spreader is made using an O-ring and screws; spacers are added to brace the two panels. Finally, every surface that is not used for flow visualization is insulated with foam to limit heat losses.

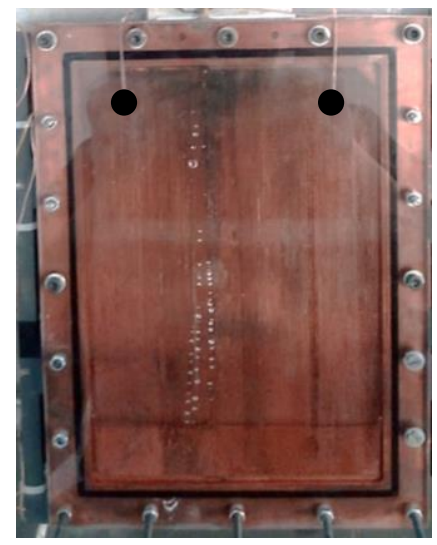

(a) transparent heat spreader [copper base, poly carbonate panel]

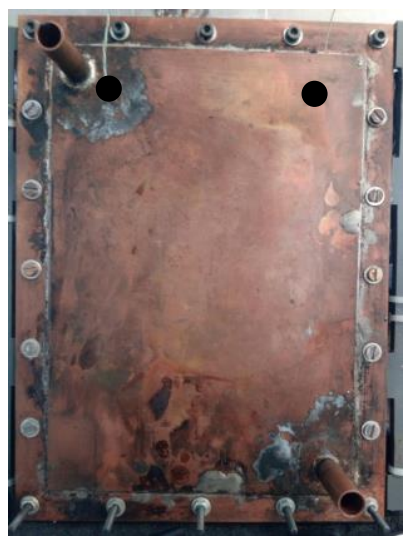

(b) copper heat spreader [copper base, copper panel without the insulation]

Figure 3. Front pictures of the heat spreader. 
Both versions of the spreader use the same copper base with the same heat sink and heat source. A common set of $10 \mathrm{~K}$ type thermocouples with a precision of $\pm 0.1{ }^{\circ} \mathrm{C}$ measures the outer wall temperature on the heated side, allowing to obtain a temperature distribution on the entire height of the heat spreader, as illustrated in the schematics of Figure 2 . In this configuration, the distance between the evaporator and condenser sections is too short to enable the presence of an actual adiabatic section; two wall-crossing K-type thermocouples are therefore added to each front panel to measure the temperature inside the cavity, relatively far from the liquid film, in the upper section of the spreader (as indicated by two black dots in Figure 3a) and thus provide an estimation of the saturation temperature $T_{\text {sat }}$.

The temperature and flow rate of the water-cooled heat sink are controlled by a thermo-regulated bath, with cooling water

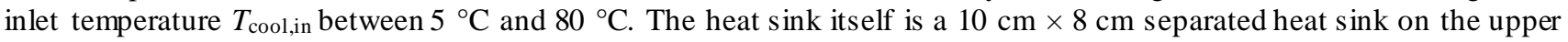
section of the back wall, as illustrated in Figure $2 \mathrm{a}$.

The heat source is made of a $10 \mathrm{~cm} \times 6 \mathrm{~cm}$ aluminum block with three heating cartridges powered by a power supply delivering up to $600 \mathrm{~W}$; these dimensions were chosen to simulate a power module for an existing application. The heat source is insulated and installed on the lower half of the back wall of the heat spreader. Heat fluxes up to $10 \mathrm{~W} / \mathrm{cm}^{2}$ (calculated with the heat source surface) were supplied to the thermosyphon.

Electrical heating power measured with the current and voltage, and temperatures from the spreader and the heat sink are recorded by a Keithley data acquisition system and monitored on a LabVIEW interface.

In this configuration, the parameters that can be set by the experimenter are the filling ratio $F R$ (given as a percentage of the spreader volume), the cooling water inlet temperature $T_{\text {cool,in }}$ (heat sink), the heating power $Q$ (heat source) and the inclination angle of the device $\theta$. Corresponding ranges of settings are summarized in Table 1.

\begin{tabular}{|l|c|c|}
\hline Set parameters & Notation & Experimental range \\
\hline Filling ratio & $F R$ & $0-100 \%$ \\
\hline Heating power & $Q$ & $0-600 \mathrm{~W}$ \\
\hline Water cooling inlet temperature & $T_{\text {cool, in }}$ & $5^{\circ} \mathrm{C}-80{ }^{\circ} \mathrm{C}$ \\
\hline Inclination angle & $\theta$ & $0^{\circ}-180^{\circ}$ \\
\hline
\end{tabular}

Table 1. Experimental ranges for operating parameters.

\subsection{Data reduction}

The temperature difference along the heat spreader $\Delta T_{\text {spreader }}$ can be considered as a preliminary indication of its thermal performance. It is written according to the outer wall temperatures at the evaporator and at the condenser, with the notations presented in Figure 4:

$\Delta T_{\text {spreader }}=T_{\mathrm{w} \text {,evap }}-T_{\mathrm{w}, \mathrm{cond}}$

The thermal resistance of the heat spreader $R_{\text {spreader, }}$ that is primarily used to characterize its thermal performance, is expressed with the temperature difference $\Delta T_{\text {spreader }}$ and the heat load $Q$ supplied in the evaporator section:

$R_{\text {spreader }}=\frac{\Delta T_{\text {spreader }}}{Q}$

Considering the thermal conduction in the wall, the global thermal resistance can be written according to a conduction resistance $R_{\text {conduction }}$ and two thermal resistances associated with phase change in the evaporation and condensation areas, $R_{\text {evap }}$ and $R_{\text {cond }}$, respectively, as proposed by Lips et al. (2009) and as illustrated in Figure 4 with an equivalent circuit.

Most studies do not discriminate between phase change and conduction heat transfers and calculate evaporation and condensation thermal resistances using the total heat load $Q$ supplied to the device. For the present two-phase heat spreader, it is however necessary to estimate the heat flux associated with conduction $Q_{\text {conduction }}$ in order to properly characterize phase change mechanisms.

The thermal resistance corresponding to the conduction in the spreader $R_{\text {conduction }}$ can be calculated from temperature and heat load measurements obtained for an empty thermosyphon:

$R_{\text {conduction }}=\left(\frac{\Delta T_{\text {spreader }}}{Q}\right)_{\text {empty }}$

According to Figure 4, the heat load $Q_{\varphi}$ corresponding to phase change heat transfer is therefore equal to:

$Q_{\varphi}=Q\left(1-\frac{R_{\text {spreader }}}{R_{\text {conduction }}}\right)$ 


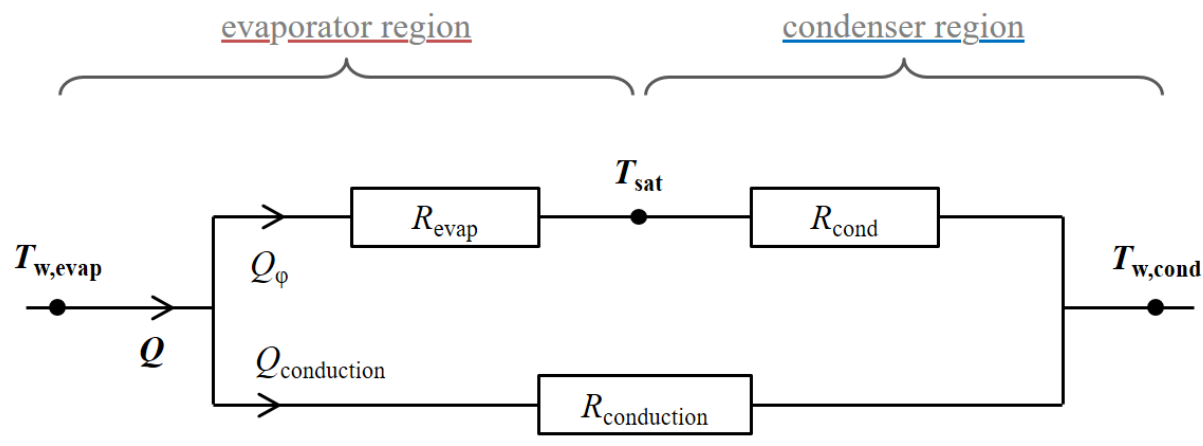

Figure 4. Equivalent circuit for the spreader thermal resistance.

This heat load associated with phase change is used for the calculation of heat transfer coefficients $h_{\text {evap }}$ and $h_{\text {cond }}$ in the evaporator region and condenser region, respectively, with the addition of the saturation temperature $T_{\text {sat }}$ in order to characterize evaporation heat transfer and condensation heat transfer in the spreader:

$h_{\text {evap }}=\frac{Q_{\varphi}}{A_{\text {evap }}\left(T_{\text {w,evap }}-T_{\text {sat }}\right)} \quad$ and $\quad h_{\text {cond }}=\frac{Q_{\varphi}}{A_{\text {cond }}\left(T_{\text {sat }}-T_{\text {w,cond }}\right)}$

where $A_{\text {evap }}$ and $A_{\text {cond }}$ are the surfaces of the evaporator and condenser sections, respectively.

Analysis of temperature profiles provides additional information about the spreader thermal performance, such as maximal rewetted height and preferential areas for heat source location, which can be compared to more accurate values processed from flow visualizations.

Uncertainties need to be properly determined to draw relevant quantitative conclusions on the influence of operating parameters on the spreader thermal performance.

The uncertainty in the spreader thermal resistance depends on the uncertainties in the wall temperatures and applied heat flux. Since the temperature distributions on the evaporator and condenser sections are relatively uniform, the wall temperatures $T_{\mathrm{w}, \text { evap }}$ and $T_{\mathrm{w}, \mathrm{cond}}$ are obtained by averaging the temperature measurements along these sections. The estimation of the uncertainty in the heat load is more complex. An energy balance is performed to quantify heat losses:the input power at the evaporator section $Q=Q_{\text {in }}$ (obtained using the supply voltage and current measurements) is compared to the heat load removed at the condenser $Q_{\text {out }}$ :

$Q_{\text {out }}=\dot{m} C p\left(T_{\text {cool out }}-T_{\text {cool,in }}\right)$

The corresponding experimental uncertainty in $Q$ was found to be around $15 \%$ for low power settings and $7 \%$ for high power settings, which is consistent with the usual order of magnitude for heat losses in this type of configuration.

The resulting uncertainty in the spreader thermal resistance $\delta R_{\text {spreader }}$ was then calculated with the expression:

$\frac{\delta R_{\text {spreader }}}{R_{\text {spreader }}}=\sqrt{\left(\frac{\delta Q}{Q}\right)^{2}+\left(\frac{\delta \Delta T_{\text {spreader }}}{\Delta T_{\text {spreader }}}\right)^{2}}$

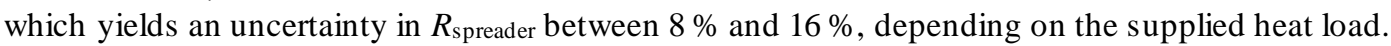

The uncertainty in the heat transfer coefficients is obtained in the same way but is much larger than for the thermal resistance: indeed, the calculation of $h_{\text {evap }}$ and $h_{\text {cond }}$ requires among others a precise measurement of the saturation temperature $T_{\text {sat }}$ and a proper determination of the heat load $Q_{\varphi}$ associated with evaporation and condensation processes.

The saturation temperature is obtained by averaging the measurements provided by two thermocouples placed inside the cavity at the same height, as shown by the black dots in Figure 3. Given the uncertainty in the measurement and the differences between the two sensors, a precision of $\pm 2 \mathrm{~K}$ is considered for this quantity.

The uncertainty in the phase change heat load $Q_{\varphi}$ depends on the uncertainty in the spreader thermal resistance (for an empty device and a filled thermosyphon) and on the uncertainty in the global heat input. It ranges between 15 and $30 \%$.

Neglecting the uncertainty in the geometrical parameters yields an uncertainty in the heat transfer coefficients between $16 \%$ (evaporation heat transfer coefficients at high heat flux) and $40 \%$ (condensation heat transfer coefficients at low heat flux). Despite the lack of precision in some configurations, the calculations of the heat transfer coefficients provide suitable estimations for the characterization of evaporation and condensation mechanisms and comparison with literature correlations developed for two-phase thermosyphons. 
The uncertainties in the main experimental and calculated quantities are summarized in Table 2. Measurement uncertainties in other operating parameters can be mentioned, but their effect on the estimation of the thermal performance is hardly quantifiable. It is the case, for instance, for the filling ratio (measured with a precision of $\pm 1 \mathrm{~mL}$, corresponding to an uncertainty between $3 \%$ and $20 \%$ ) or inclination angle.

\begin{tabular}{|l|c|c|}
\hline Quantities & Notation & Uncertainty \\
\hline Experimental & $Q$ & $\begin{array}{r}2-40 \mathrm{~W} \\
7-15 \%\end{array}$ \\
\hline Global heat load & $T_{\text {sat }}$ & $2{ }^{\circ} \mathrm{C}$ \\
\hline Saturation temperature & \multicolumn{2}{|c|}{} \\
\hline Calculated & $R_{\text {spreader }}, R_{\text {conduction }}$ & $8-16 \%$ \\
\hline Thermal resistance & $Q_{\varphi}$ & $15-30 \%$ \\
\hline Phase change heat load & $h_{\text {evap }}, h_{\text {cond }}$ & $16-40 \%$ \\
\hline Heat transfer coefficient &
\end{tabular}

Table 2. Uncertainties for experimental and calculated values.

\section{RESULTS AND DISCUSSION}

This section presents the experimental results obtained with the different heat spreaders. Flow regime visualizations are used to understand the operating principle of a flat confined thermosyphon and to highlight the high coupling between boiling and condensation processes while the influence of various parameters on the thermal resistance is assessed to characterize its thermal performance. Comparisons are drawn with available literature correlations.

\subsection{Flow visualizations and operating principle}

The confinement of the working fluid inside the two-phase thermosyphon is ensured by choosing an inner thickness $e$ close to the capillary length of the working fluid $l_{\text {cap }}$, which is validated by the calculation of the Bond number $B o$ that allows to compare the effects of gravitational forces and capillary forces and can be expressed according to these two characteristic lengths:

$$
B o=\frac{\left(\rho_{\text {liq }}-\rho_{\text {vap }}\right) g e^{2}}{\sigma}=\frac{e^{2}}{l_{\text {cap }}{ }^{2}}
$$

For water, the capillary length $l_{\text {cap }}$ is equal to $2.7 \mathrm{~mm}$. With a $3 \mathrm{~mm}$ inner thickness, a Bond number of 1.2 is achieved, which confirms that the surface tension forces are not negligible unlike in unconfined systems without capillary structure, and that the confinement induces a new force balance with changes in flow patterns and thermal performance.

Visualizations of flow regimes are therefore necessary to understand the underlying boiling mechanis ms and correlate thermal performance with thermohydraulic phenomena. Due to experimental obstacles and specificity of each device and configuration, they are however difficult to obtain, and complete flow pattern maps are rarely provided. In the present study, series of tests with the transparent heat spreader were conducted to gather information on flow regimes and effects of confined boiling, as illustrated in Figure 5, for various heating and cooling conditions. Two main flow patterns were observed depending on heating conditions.

For low saturation temperatures (typically $T_{\mathrm{sat}}<60^{\circ} \mathrm{C}$ ), large and scarce bubbles (as delimited in Figure 5b) nucleate in the evaporation area and rise to the top of the device where they condense. The frequency of bubble appearance in this regime increases with the heat flux. For high values of heat input, the large amounts of liquid that are periodically vaporized and rapidly propelled to the condenser section seem to prefigure geyser boiling as described by Tong et al. (2015).

At high saturation temperature (typically $T_{\text {sat }}>60{ }^{\circ} \mathrm{C}$ ), very numerous and small bubbles nucleate in the evaporation area, with a high appearance frequency, as observed in Figure $5 \mathrm{c}$ where the heat source takes up to two thirds of the spreader width and where some bubbles are highlighted in the middle. In configurations with narrow heat sources, some of these nucleated bubbles are deviated to the sides of the device by the condensate returning to the evaporator as they rise to the condenser section, creating a "bubble tree". Depending on the test conditions, large coalesced bubbles can also be observed above this tree of small bubbles. 


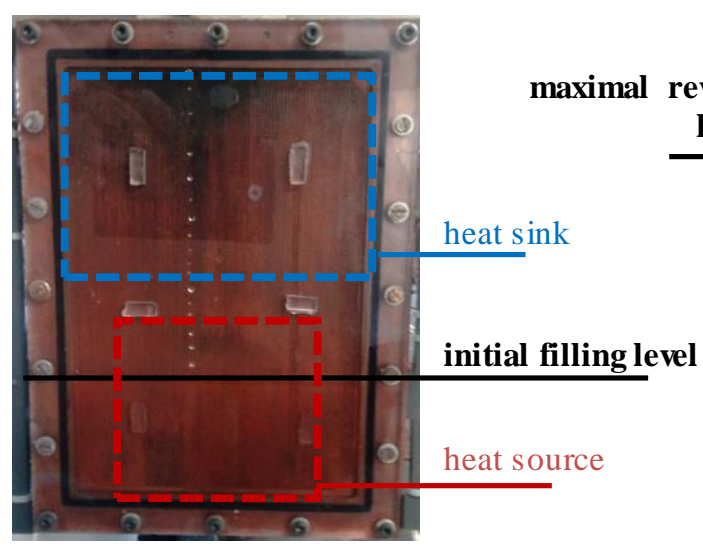

(a) without heating

Figure 5. Flow visualizations with the transparent heat spreader for $Q=500 \mathrm{~W}$.

The two flow regimes differ by the frequency and size of nucleated bubbles (periodic detachment of large bubbles at low saturation temperature, and continuous nucleation of small bubbles at high saturation temperature) but both flow pattems lead to an increase in the rewetted height, as illustrated in Figure 5 with the difference between the initial liquid level (corresponding to a filling ratio of $30 \%$ of the spreader volume) and the maximal wetted height.

This rewetting ensures that there is no dry-out of the liquid film and no wall overheating, even in the portion of the evaporator section that is not immerged in the liquid pool. It can be explained by considering the operating principle of the confined flat thermosyphon that is illustrated in the schematics (front view and cross-section) of Figure 6, with the example of a relatively narrow heat source corresponding to an evaporation area not as wide as the spreader.

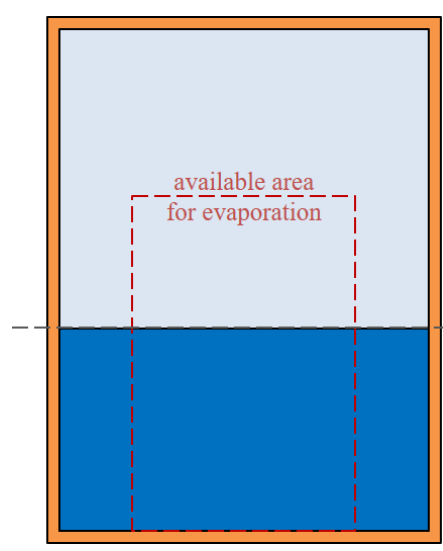

(a) without heating

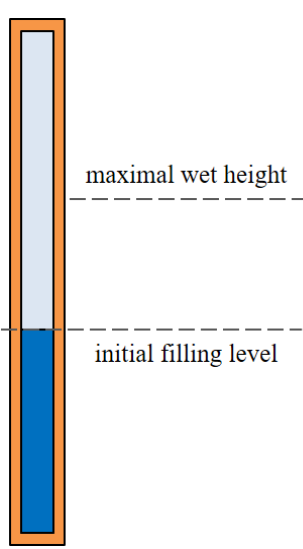

(b) low saturation temperature

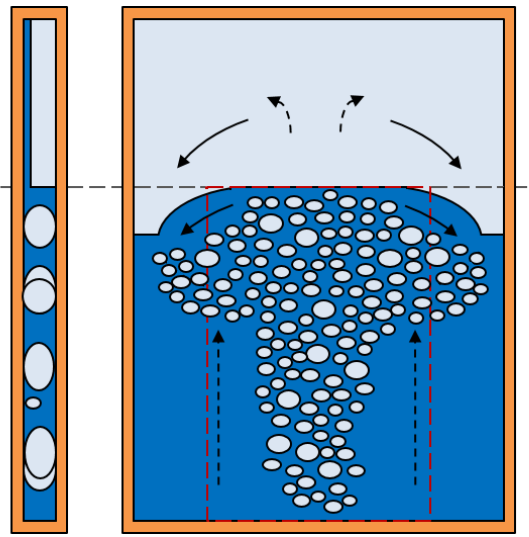

(c) high saturation temperature

Figure 6. Heat spreader operating principle.

The operating principle of the two-phase heat spreader is described in a patent that was filed for the particular device that is studied here (Lips et al, 2017). In the confined space, the interaction between gravitational, buoyancy and capillary forces induces a liquid flow that rewets a large area of the inner wall which is not in contact with the liquid before operation. Indeed, in the case of low saturation temperatures, large bubbles nucleating in the evaporation area or coalescing in the liquid pool are confined and tend to "push" the liquid above upwards as they ascend to the condenser section. In the case of higher saturation temperatures, the significant amount of vapor produced by dense fully developed nucleation also contributes to an increase of the rewetted height. The liquid returns to the evaporator section under the form of a film, mostly in the side sections.

The rewetted surface depends on the initial filling level and volume of nucleated bubbles:in the cas e of low filling ratios with moderate heat fluxes, the rewetted height is not very significant. Optimum rewetting is achieved with relatively consequent filling ratios (typically between $25 \%$ and $80 \%$ of the spreader volume, according to flow visualization s) and boiling regimes with dense fully developed nucleation. In these configurations, the rewetted height can reach twice the length corresponding to the initial filling level. As long as one heat source is kept under the liquid pool level, heat sources can be added on the whole rewetted height, therefore extending the available evaporation area and allowing the heat spreader not to be as constrained as classical thermosyphons in regards to the heat source location. 


\subsection{Heat spreader performance}

As previously mentioned, the heat spreader thermal resistance is affected by numerous operating parameters. In the present work, the influence of the heating power, filling ratio, inclination angle and saturation temperature is investigated with the copper heat spreader to as ses s the performance of the novel confined flat TPCT. Unless mentioned otherwise, the default orientation of the two-phase heat spreader corresponds to a vertical position $\left(\theta=90^{\circ}\right)$. Graphical representations of uncertainties in the main quantities are provided with example of error bars for curves corresponding to $40 \%$ filling ratio only, for readability purpose.

\section{Influence of heating_power and filling ratio}

Figure 7 presents examples of temperature distributions with steady state temperatures at different locations on the outer back wall, for various filling ratios $F R$, for various heating powers $Q$, and in a vertical position. Measurements corresponding to thermocouples in the middle region of the evaporator section and condenser section are relatively constant, which justifies the averaging of these values to obtain the respective temperatures $T_{\mathrm{w}, \text { evap }}$ and $T_{\mathrm{w}, \mathrm{cond}}$. The short distance between the heat source and the heat sink does not allow to get a proper estimation of the saturation te mperature, as can be seen from the graphics, which justifies the use of additional thermocouples in the cavity.

The temperature difference between the evaporator and condenser sections is representative of the spreader thermal performance. At fixed filling ratio and inlet cooling temperature, it increases with the supplied heat load. For $T_{\text {cool, in }}=40{ }^{\circ} \mathrm{C}$, all filling ratios considered, a maximal temperature difference $\Delta T_{\text {spreader }}$ of $45 \mathrm{~K}$ was measured between the evaporator and condenser for a $10 \mathrm{~W} / \mathrm{cm}^{2}$ heat flux.

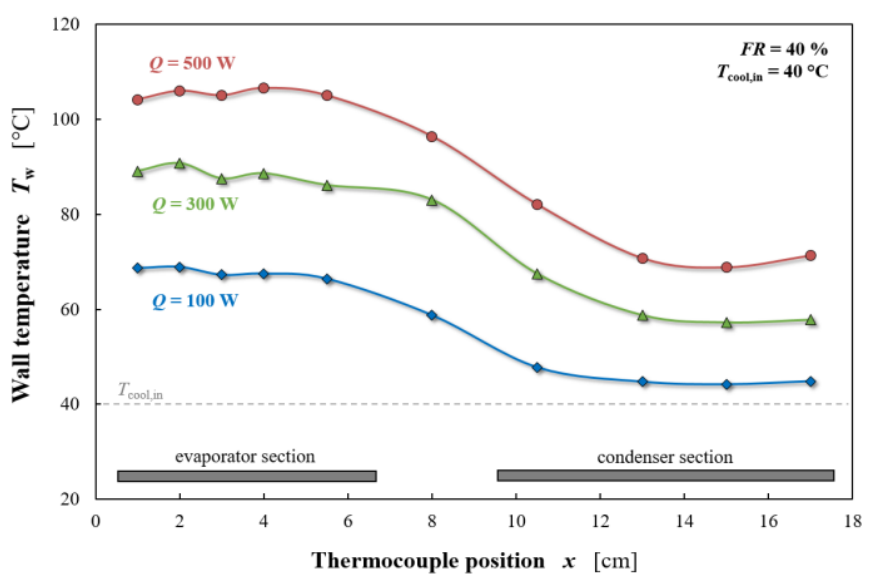

(a) $F R=40 \%$

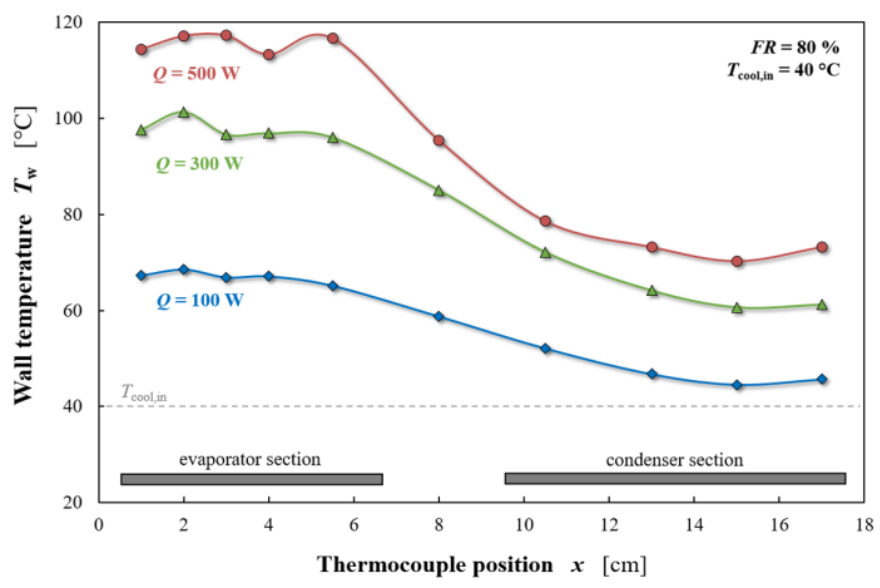

(b) $F R=80 \%$

Figure 7. Outer wall temperature distribution for various filling ratios and input powers $-T_{\text {cool, in }}=40^{\circ} \mathrm{C}, \theta=90^{\circ}$.

Figure 8 presents an example of evolution of the spreader thermal resistance according to the heating power up to $10 \mathrm{~W} / \mathrm{cm}^{2}(600 \mathrm{~W})$ for four filling ratios, at constant inlet cooling temperature $T_{\text {cool,in }}=40^{\circ} \mathrm{C}$, with error bars for the $40 \%$ filling ratio. The thermal behavior of the system is non-linear with low heat resistance for high heat fluxes and a slight degradation of thermal performance for lower heat fluxes. Low supplied heat load $(Q<100 \mathrm{~W})$ mostly correspond to heating conditions that do not allow boiling to start. Thermal resistances down to $0.07 \mathrm{~K} / \mathrm{W}$ were reached for the maxima 1 tested heat flux around $10 \mathrm{~W} / \mathrm{cm}^{2}$, as can be seen for the curve corresponding to the $40 \%$ filling ratio.

As observed by comparing Figures $7 \mathrm{a}$ and $7 \mathrm{~b}$, the spreader thermal performance is strongly affected by the filling ratio. Parametric runs were therefore conducted for various filling ratios between $20 \%$ and $80 \%$ of the spreader volume. Figure 8 shows that, in the studied regimes, the thermal resistance increases with the filling ratio, with the exception of a thermal performance degradation at very low filling ratio as illustrated with the curve for $F R=20 \%$ that exhibits a liquid level too low to correctly rewet the whole evaporator section. An optimum filling ratio could therefore be determined for each set of cooling and heating conditions. In the case illustrated in Figure 8, this optimum filling ratio appears to be around $40 \%$ of the spreader volume, i.e. around $100 \%$ of the evaporator volume. Zhang et al. (2013) also found out that an optimum filling ratio allows an enhancement of heat transfer by promoting inter-related boiling and condensation processes.

However, although smaller filling ratios (typically around $40 \%$ ) seem to correspond to better performance, they also mean less available surface for heat source location; a compromise has then to be reached between heat transfer capability and degree of freedom on heat source positioning. 
Experiments were performed to investigate potential hysteresis behavior, with nucleate boiling being sustained down to temperature differences below the level needed to initiate boiling. Figure 9 presents an example of hysteretic loop with error bars, where the thermal resistance was first characterized with increasing heat fluxes and then with decreasing heat fluxes. Hysteresis effect depends on the filling ratio, but it is rather limited on the present temperature ranges: the maxima 1 difference between the two curves corres ponds to the experiments with the $40 \%$ filling ratio that are presented here and is not significant compared to the uncertainty in the thermal resistance. This conclusion was also reached by Ong et al. (1997) for vertical TPCT using water.

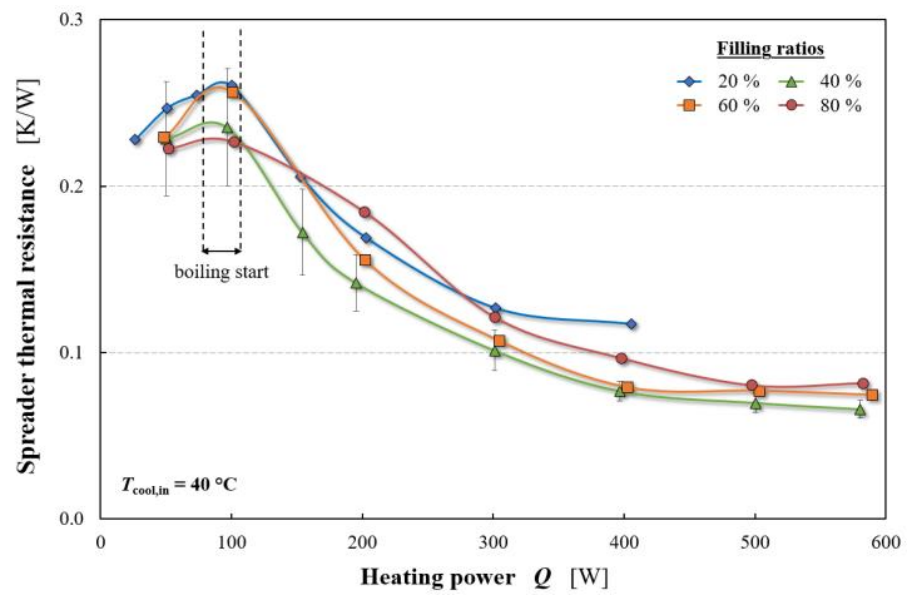

Figure 8. Evolution of the spreader thermal resistance with the heating power for various filling ratios.

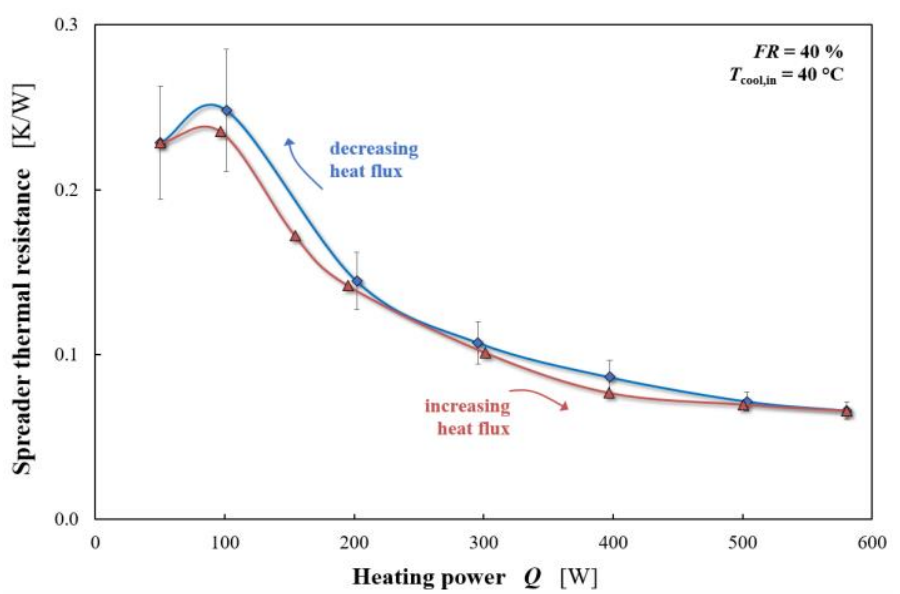

Figure 9. Hysteresis effect for $F R=40 \%$.

The thermal resistance measurements provided by the flat confined thermosyphon can be compared to literature values obtained with flat capillary heat pipes of similar inner dimensions or two-phase thermosyphons in comparable operating conditions. Some literature values are provided for copper-water devices in Table 3.

\begin{tabular}{|c|c|c|c|c|}
\hline References & $\boldsymbol{T}_{\text {cool, in }}\left[{ }^{\circ} \mathrm{C}\right]$ & $\boldsymbol{e}[\mathrm{mm}]$ & $q \quad\left[\mathrm{~W} / \mathrm{cm}^{2}\right]$ & $\boldsymbol{R}_{\text {spreader }}[\mathrm{K} / \mathrm{W}]$ \\
\hline \multicolumn{3}{|l|}{ Flat plate capillary heat pipes } & \multicolumn{2}{|c|}{ as reported by $\mathrm{Li}$ and $\mathrm{Lv}$ (2016) } \\
\hline Zaghdoudi et al. (2011) & 40 & 0.5 & 4.2 & $\sim 0.72$ \\
\hline $\mathrm{Li}$ and $\mathrm{Lv}$ (2016) & 35 & 1 & 100 & 0.196 \\
\hline De Paiva et al. (2011) & 56 & 1.4 & 7.5 & $\sim 0.4$ \\
\hline Tsai et al. (2013) & 40 & 1.4 & 44.2 & 0.869 \\
\hline Lips et al. (2010) & 40 & 2 & 10 & 0.24 \\
\hline \multicolumn{5}{|l|}{ Two-phase thermosyphons } \\
\hline Present study & 40 & 3 & 10 & 0.07 \\
\hline Jouhara and Robinson (2010) & - & $\begin{array}{c}6 \\
\text { inner diameter }\end{array}$ & $260 \mathrm{~W}$ & 0.14 \\
\hline
\end{tabular}

Table 3. Comparis on of thermal resistances for various copper-water devices in the literature.

For instance, $\mathrm{Li}$ and Lv (2016) listed experimental studies including investigation s of thermal resistance of flat plate heat pipes that can be considered as confined. Experiments that were performed with copper-water devices on similar ranges of heat flux and cooling temperature exhibit thermal resistances between $0.2 \mathrm{~K} / \mathrm{W}$ and $0.9 \mathrm{~K} / \mathrm{W}$, which is 3 to 14 times worse than what the present heat spreader delivered in optimum configuration. These values highlight an enhancement of thermal performance for the gravity-assisted device compared to flat plate capillary heat pipes that are still limited in terms of heat transfer capability because of their wick.

Experimental results are in better agreement with the values of thermal resistance obtained by Jouhara and Robinson (2010) in a small diameter TPCT filled with water and presenting very similar dimensions: the authors validated the confinement of their device by comparing its inner diameter to the expected bubble departure diameter and measured overall thermal resistances down to $0.14 \mathrm{~K} / \mathrm{W}$ for a $260 \mathrm{~W}$ supplied heat load and cooling temperature of $35{ }^{\circ} \mathrm{C}$. The consistency of both studies is interesting, considering that only the geometry significantly varies. 


\section{Influence of inclination}

The effect of the spreader inclination is also investigated. The experimental set-up is built to investigate inclination angle $\theta$ between $0^{\circ}$ (with evaporator on top) and $180^{\circ}$ (evaporator on the bottom), $90^{\circ}$ corresponding to the vertical usual operating configuration for a two-phase thermosyphon. The $0^{\circ}$ position is expected to be the most unfavorable one, with the evaporator wall not being in contact with the liquid pool; classical TPCTs do not operate in horizontal position and rarely exhibit good thermal performance when strongly inclined in general.

Despite the large range of inclination angles that was tested for various heating and cooling conditions, the effect of inclination on thermal resistance is hardly noticeable for start-ups in vertical position, as presented in Figure 10a for three different filling ratios. Indeed, the uncertainty in the spreader thermal resistance does not allow to conclude on the very small differences induced by inclination changing. In limit cases (for example at very low filling ratio plus high heat flux), changes in the flow pattern were observed with nucleation reduction when inclining the s preader from $90^{\circ}$ to $180^{\circ}$ but they rarely led to an important degradation of thermal performance. Even in the least favorable horizontal position, no operation interruption occurred, which confirms that the gravitational forces are not dominant in the force balance. A maximal increase of $17 \%$ in the thermal resistance was measured in the worst position s tested (horizontal with evaporator on top, at low filling ratios) compared to the vertical configuration for standard operation, which is not even significant if the uncertainty in the thermal resistance is taken into account.

Experimental tests were performed with start-up in inclined positions. Start-up was not achieved for most of the runs at low filling ratios and high heat fluxes - corresponding to already degraded performance in vertical operation. For limited inclinations and / or high filling ratio, operation starts with high to moderate thermal resistances depending on the configuration and changes in the flow regime are sometimes observed as the thermosyphon inclination is changed.

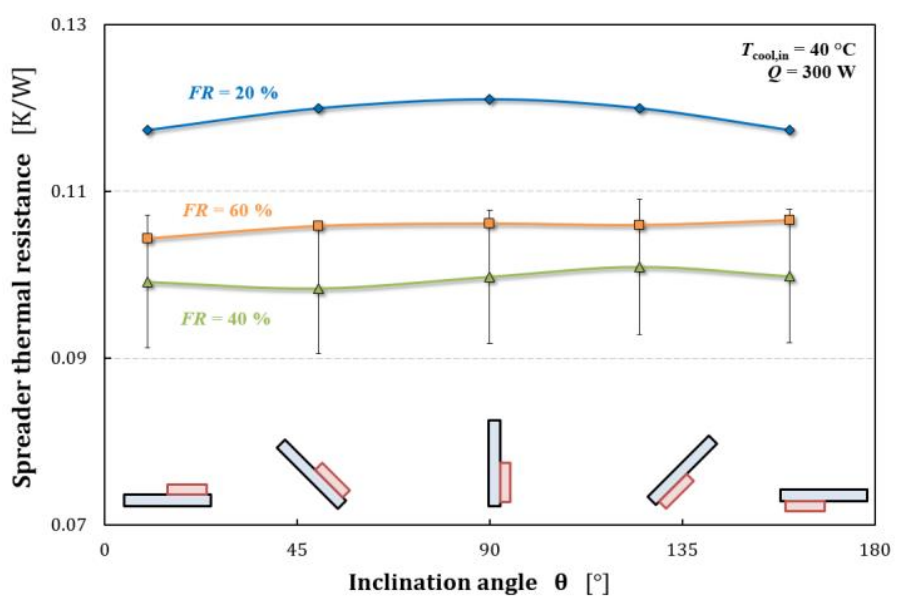

(a) spreader thermal resistance according to the inclination angle for various filling ratios.

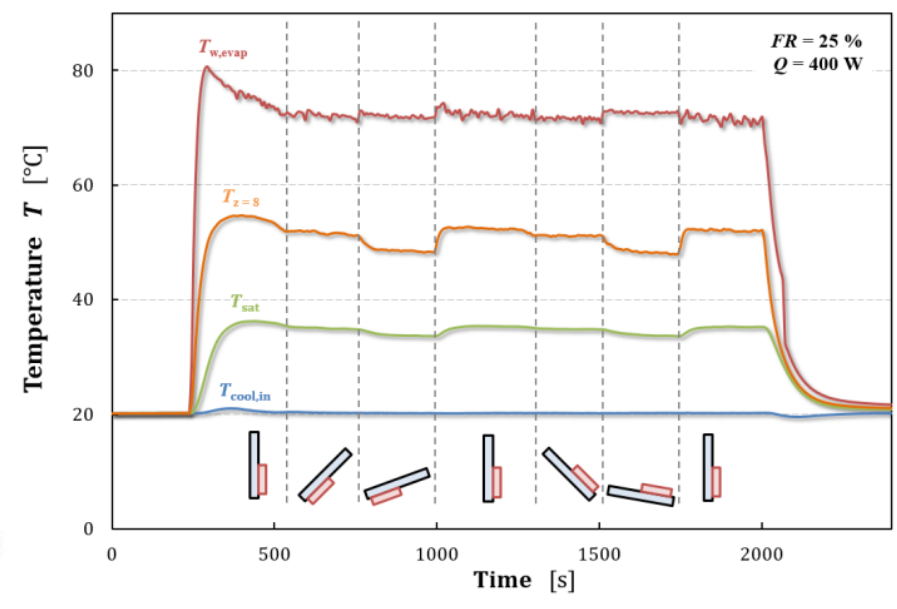

(b) example of temperature evolutions with changes in the inclination angle.

Figure 10. Influence of inclination on the heat spreader thermal performance, start-up in vertical position. (bottom: corresponding positions of heat spreader and heat source)

The low sensitivity to inclination may be explained by the system confinement that causes the internal wall on the evaporator side to be still correctly wetted by the liquid on a sufficient portion of its height even in the worst configurations, unlike in the case of classical thermosyphons. This is illustrated in Figure 10b (plotted for an inlet cooling temperature of $20^{\circ} \mathrm{C}$ to better highlight the different trends) by the relative uniformity of the maximal temperature at the evaporator $T_{\mathrm{w}, \text { evap }}$ that remains almost constant despite significant changes in $\theta$, whereas the influence of the inclination can clearly be seen on the wall temperature measurement just above the evaporator section $T_{x=8}$ (acquired by the thermocouple at $x=8 \mathrm{~cm}$ between the heat source and heat sink), depending on which height is rewetted by the liquid in the inclined spreader.

These results are quite different from what is usually found in the literature for classicalTPCTs. As previously mentioned, the few studies that investigate the effect of inclination angle (Noie et al, 2007; Hu et al, 2016; Li and Lv, 2016...) all conclude that this parameter has an important influence on the thermal performance and highlight the existence of an optimum position between vertical position and horizontal position with evaporator on the bottom. In the present work, the confinement allows to free the spreader from issues related to changes in inclination: operation is possible in any configuration with moderate degradation in the performance as long as start-up happens in (near) vertical orientation.

\section{Influence of saturation temperature}

The effect of the saturation temperature on flow patterns has already been mentioned in the section about flow visualizations: its influence on boiling processes and nucleation is clearly visible and changes in this operating parameter are therefore expected to significantly affect the thermal performance. Unfortunately, accurate measurements of the 
saturation temperature are difficult to perform and its impact on the thermal res istance is often assessed through simple adjustments of the cooling temperature in the condenser region. In the present work, the saturation temperature is estimated with an average value of two vapor temperature measurements provided by thermocouples inside the cavity, and varied by setting different values of inlet cooling temperature $T_{\text {cool,in }}$.

Figure 11 presents the evolution of the spreader thermal resistance according to the saturation temperature for four filling ratios. The measurement points around each vertical grey line were obtained by setting the inlet cooling water temperature at the value written beneath it. As can be seen, the thermal resistance decreases with increasing saturation temperature and the evolution is almost linear, with similar slopes for all filling ratios. The same conclusion on the influence of the filling ratio can be drawn as previously mentioned, with an optimum $F R$ around $40 \%$. Although increasing the saturation temperature leads to better performance in terms of thermal resistance, it also causes a global increase in the wall temperature, which might reach high values that are not suitable for the application, especially for the thermal management of electronic components. A compromise has then to be done depending on the specifications.

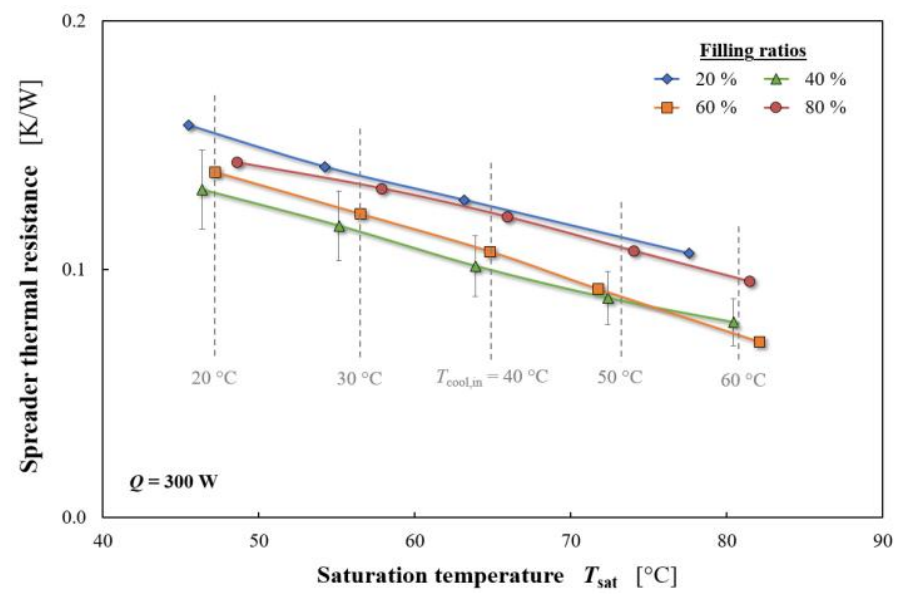

Figure 11. Evolution of the spreader thermal resistance with the saturation temperature for various filling ratios .

The evolution of the thermal performance with the saturation temperature can be correlated with flow visualizations: lower saturation temperatures (typically $T_{\text {sat }}<60{ }^{\circ} \mathrm{C}$ ) correspond to flow regimes with nucleation of large bubbles at low frequency and therefore to limited heat transfer capability while higher saturation temperatures $\left(T_{\text {sat }}>60{ }^{\circ} \mathrm{C}\right)$ promote nucleation of small and dense bubbles enhancing heat transfer, as reported by Bergles and Rohsenow (1964).

As explained, experimental studies on thermosyphons and flat heat pipes rarely investigate the influence of saturation temperature on thermal performance on extensive ranges; most of them often provide thermal resistance data for a given inlet cooling temperature only. Nevertheless, the few studies listed by Jafari et al. (2016) and Li and Lv (2016) which as ses sed the influence of cooling conditions on a thermosyphon or flat heat pipe thermal resistance found out similar trends, i.e. a degradation of the performance with a decrease of the saturation temperature.

\subsection{Heat transfer analysis}

As described in the data reduction section, evaporation and condensation heat transfer coefficients are processed to characterize two-phase mechanisms inside the device: since the behavior in evaporation and condensation sections is the main factor determining proper operation, it is important to calculate them with the heat flux associated to phase change, by taking into account the conduction in the spreader walls, as stated in Equation 4.

In this section, experimental results about evaporation and condensation heat transfer coefficients are presented. Comparisons are drawn with relevant semi-empirical correlations from the literature. As previously, error bars are indicated on the curve corresponding to the $40 \%$ filling ratio. Unless mentioned otherwise, the spreader is in vertical position.

\section{Experimental heat transfer coefficients}

Evaporation and condensation heat transfer coefficients are plotted according to the supplied heat load in Figures 12a and $12 \mathrm{~b}$, respectively, for four different filling ratios, in a vertical position.

On the present range of experimental parameters, the evaporation heat transfer coefficient continuously increases with the heat flux, with an almost-linear behavior once boiling has started in the evaporator region. Values between $400 \mathrm{~W} / \mathrm{K} / \mathrm{m}^{2}$ and $3000 \mathrm{~W} / \mathrm{K} / \mathrm{m}^{2}$ are obtained for heat fluxes between $1.6 \mathrm{~W} / \mathrm{cm}^{2}(100 \mathrm{~W})$ and $10 \mathrm{~W} / \mathrm{cm}^{2}(600 \mathrm{~W})$. $h_{\text {evap }}$ is significantly affected by the filling ratio that determines the liquid level and the rewetted portion of the heated wall. As already visible in Figure 8 with the thermal resistance, an optimum filling ratio of $40 \%$ can be set to maximize the evaporation heat transfer and minimize the global thermal resistance; this moderate filling ratio corresponds to a liquid pool occupying 
around $100 \%$ of the evaporation area. Lower filling ratios do not allow a proper rewetting of the whole heated section, and significantly higher filling ratios induce a flooding of the device and a degradation of its thermal performance.

Condensation heat transfer coefficient is also strongly influenced by the heat flux and the filling ratio that affect the thickness of the liquid film. Values between $800 \mathrm{~W} / \mathrm{K} / \mathrm{m}^{2}$ and $8000 \mathrm{~W} / \mathrm{K} / \mathrm{m}^{2}$ are obtained for heat fluxes between $1.2 \mathrm{~W} / \mathrm{cm}^{2}$ and $10 \mathrm{~W} / \mathrm{cm}^{2}$. Once boiling has started, $h_{\text {cond }}$ rapidly increases with $Q$ before it reaches a stable value; it seems that the lower the filling ratio is, the faster this plateau is reached. Despite the significant uncertainty in the condensation heat transfer coefficient (due to a small difference between the saturation temperature and the wall temperature in the

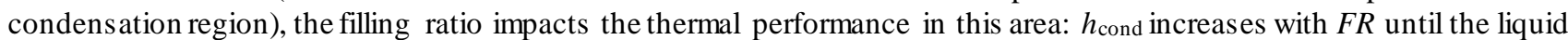
level is too high and floods the condensation area as well, as noticeable for the curve at $80 \%$ filling ratio. Similar trends according to the filling ratio were observed by Noie (2005).

Therefore, intermediate filling ratios around $40 \%-60 \%$ (corresponding to liquid levels about the same height as the evaporation area) seem to be relevant settings to maximize heat transfer performance both in the evaporator and condenser sections. They also correspond to a reasonable degree of freedom in the positioning of heat sources.

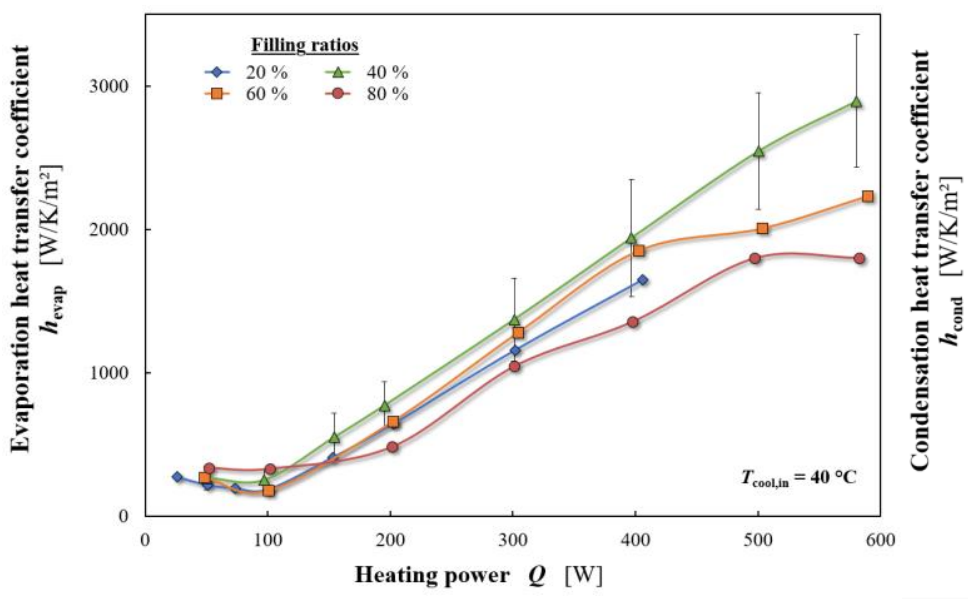

(a) evaporation heat transfer coefficient.

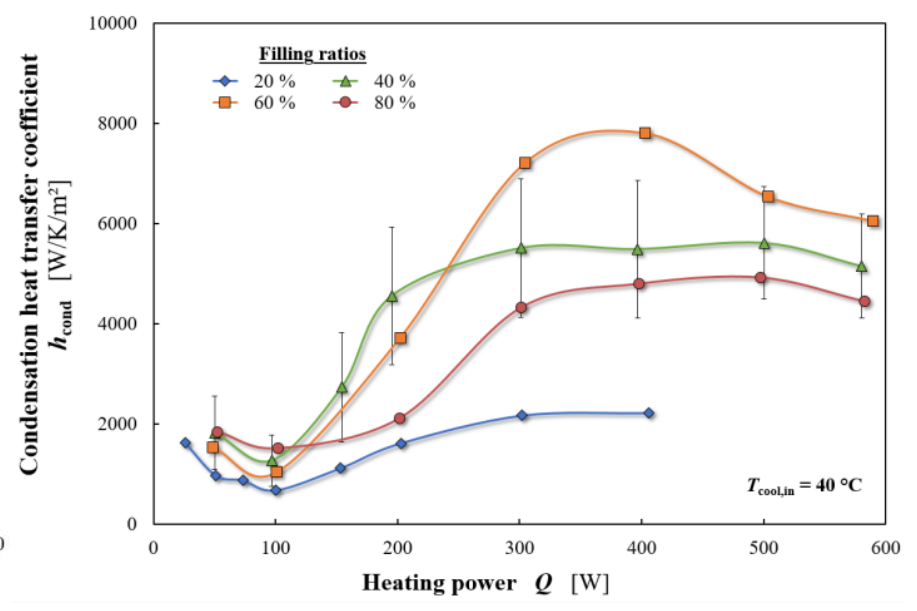

(b) condensation heat transfer coefficient.

Figure 12. Experimental heat transfer coefficients with correction for conduction effects, according to supplied heat load for various filling ratio $-T_{\text {cool, in }}=40^{\circ} \mathrm{C}, \theta=90^{\circ}$.

\section{Comparisons with literature}

The evaporation and condensation heat transfer coefficients allow to quantitatively characterize the spreader thermal performance but do not give indications about how the confinement of the fluid is affecting two-phase mechanisms. Comparisons are therefore drawn with several empirical correlations for the prediction of these quantities that were tested, adapted or developed for classical two-phase thermosyphons; these selected correlations are summarized in Table 4. Additional correlations can be found in the literature. However, most of them are merely adaptations or minor corrections of existing expressions for fitting specific experimental results. Four main correlations for the prediction of heat transfer coefficients on similar experimental ranges with water are therefore discussed for each spreader section, for readability purpose. They have been adapted to match flat designs.

Evaporation heat transfer coefficients depend on the flow regime that is observed in the evaporator section: natural convection, mixed convection or nucleate boiling, depending on the heat flux. Considering the ranges of experimental parameters in the present study, most of the runs correspond to the latter case, and only nucleate pool boiling correlations have been considered. These correlations introduce a dependency of boiling heat transfer on pressure, as proposed by Imura et al. (1983) and Kutateladze. Chowdhury et al. (1997) added a density ratio ( $\left.\rho_{\mathrm{v}} / \rho_{\mathrm{l}}\right)$ that was also used by El-Genk and Saber (1998). These expressions describe the influence of the saturation pressure (or saturation temperature) and heat flux on the evaporation heat transfer coefficient, but not of the filling ratio.

Condensation heat transfer coefficients are also impacted by changes in the operating pressure, temperature and heat flu x. The simplified model provided by Nusselt's theory stating that the heat removal occurs in the laminar condensate film for a vertical wall was tested with experimental data for water in two-phase thermosyphons, and good agreement was found (Rohsenow, 1985). Most of the correlations that were then developed for these devices are therefore based on this theory. In addition, $h_{\text {cond }}$ depends on the inclination angle and local flow velocity since it is determined by the falling condensate film and the countercurrent vapor flow. Among other authors, Wang and Ma (1991) and Hussein et al. (2001) performed experimental and theoretical studies for inclined two-phase thermosyphons. As for the evaporation heat transfer coefficient, no dependency on the filling ratio is reported in these correlations despite experimental observations of this influence, as Noie (2005) who reported that the condensation heat transfer increases with $F R$, with optimal $h_{\text {cond }}$ at $F R$ between $22 \%$ and $30 \%$ and $\theta=30^{\circ}$. 


\begin{tabular}{|c|c|}
\hline Correlations for heat transfer coefficient prediction & References \\
\hline Evaporation & nucleate pool boiling \\
\hline$h_{\text {evap }}=0.32\left(\frac{\rho_{\mathrm{l}}^{0.65} \lambda_{1}^{0.3} C p_{\mathrm{l}}^{0.7} g^{0.2}}{\rho_{\mathrm{v}}{ }^{0.25} h_{\mathrm{fg}}^{0.4} \mu_{\mathrm{l}}^{0.1}}\right)\left(\frac{P_{\mathrm{sat}}}{P_{\mathrm{atm}}}\right)^{0.3} q^{0.4}$ & Imura et al. (1983) \\
\hline$h_{\text {evap }}=0.44 \operatorname{Pr}^{0.35}\left(\frac{\lambda_{1}}{D_{\mathrm{b}}}\right)\left(\frac{\rho_{\mathrm{l}}}{\rho_{\mathrm{l}}-\rho_{\mathrm{v}}} \frac{q P_{\mathrm{sat}} \times 10^{4}}{\rho_{\mathrm{v}} g h_{\mathrm{fg}} \mu_{\mathrm{l}}}\right)^{0.7}$ & $\begin{array}{c}\text { Kutateladze } \\
\text { in Rohsenow (1985) }\end{array}$ \\
\hline$h_{\text {evap }}=11.43\left(\frac{q D_{\mathrm{b}}}{\rho_{\mathrm{v}} h_{\mathrm{fg}} v_{\mathrm{l}}}\right)^{0.72} \operatorname{Pr}^{0.42}\left(\frac{\rho_{\mathrm{v}}}{\rho_{\mathrm{l}}}\right)^{0.5}\left(\frac{\lambda_{\mathrm{l}}}{D_{\mathrm{b}}}\right)\left(\frac{D_{\mathrm{b}}}{D_{\mathrm{i}}}\right)$ & Chowdhury et al. (1997) \\
\hline $\begin{array}{c}h_{\text {evap }}=C(1+4.95) 0.44 \operatorname{Pr}^{0.35}\left(\frac{\lambda_{1}}{D_{\mathrm{b}}}\right)\left(\frac{\rho_{\mathrm{l}}}{\rho_{\mathrm{l}}-\rho_{\mathrm{v}}} \frac{q P_{\mathrm{sat}} \times 10^{4}}{\rho_{\mathrm{v}} g h_{\mathrm{fg}} \mu_{\mathrm{l}}}\right)^{0.7} \\
C=\left(\frac{\rho_{\mathrm{v}}}{\rho_{\mathrm{l}}}\right)^{0.4}\left[\frac{P_{\mathrm{sat}} v_{\mathrm{l}}}{\sigma}\left(\frac{\rho_{\mathrm{l}}{ }^{2}}{\sigma g\left(\rho_{\mathrm{l}}-\rho_{\mathrm{v}}\right)}\right)^{1 / 4}\right]^{1 / 4}\end{array}$ & El Genk and Saber (1998) \\
\hline Condensation & laminar liquid film \\
\hline$h_{\text {Nusselt }}=0.943\left(\frac{\rho_{\mathrm{l}}\left(\rho_{\mathrm{l}}-\rho_{\mathrm{v}}\right) g \lambda_{1}\left[h_{\mathrm{fg}}+0.68 C p_{\mathrm{l}}\left(T_{\text {sat }}-T_{\text {crit }}\right)\right]}{\mu_{\mathrm{l}}\left(T_{\text {sat }}-T_{\text {crit }}\right) L_{\text {cond }}}\right)^{1 / 4}$ & $\begin{array}{c}\text { Nusselt theory } \\
\text { in Rohsenow (1985) }\end{array}$ \\
\hline$h_{\text {cond }}=h_{\text {Nusselt }}\left(\frac{2 L_{\text {cond }}}{D_{\mathrm{i}}}\right)^{\cos (\theta / 4)}\left[0.54+5.68 \times 10^{-3} \theta\right]$ & Wang and Ma (1991) \\
\hline$h_{\text {cond }}=h_{\text {Nusselt }}\left(\frac{L_{\text {cond }}}{D_{\mathrm{i}}}\right)^{1 / 4(\cos \theta)^{0.358}}\left[0.997-0.334(\cos \theta)^{0.108}\right]$ & Hussein et al. (2001) \\
\hline$h_{\text {cond }}=0.85 h_{\text {Nusselt }} R e_{\mathrm{fl}}^{0.1} \exp \left(-0.000067 \frac{\rho_{\mathrm{l}}}{\rho_{\mathrm{v}}}-0.14\right)$ & $\begin{array}{l}\text { Jouhara and Robinson } \\
\text { (2010) }\end{array}$ \\
\hline
\end{tabular}

Table 4. Empirical correlations provided for the prediction of condensation and evaporation heat transfer coefficient in two-phase thermosyphons using water, as reported by Jafari et al. (2016).

Quantitative plots of evaporation and condensation heat transfer coefficients comparing experimental values and predictions from selected correlations are presented in Figure 13a and Figure 13b, respectively, for the $40 \%$ and $60 \%$ filling ratios in a vertical position.

The evolution of the evaporation heat transfer coefficient with the heat flux is correctly described by the investigated correlations, with an almost-linear increase with $Q$. The correlation developed by El-Genk and Saber (1998) provides quantitatively accurate predictions of $h_{\text {evap }}$ for low and moderate heat fluxes which correspond to a limited influence of the filling ratio. For higher heat loads, experimental evaporation heat transfer coefficients are affected by $F R$ and are significantly lower than predicted values (except with the Kutateladze correlation for experimental points at a $40 \%$ FR and $Q$ higher than $400 \mathrm{~W}$ ). In addition to the fact that these correlations were derived from different datasets and cannot be used to determine the heat transfer coefficient in all two-phase thermosyphons, the overestimation provided by the predictions can be explained by an overestimation of the heat load as sociated with phase change in the calculation of $h_{\text {evap }}$ since most authors use the global supplied heat load with no correction for conduction in the walls. A proper description of the heat transfer coefficient would also require to take into account the significant influence of the filling ratio.

According to Figure 13b, the Nusselt's theory is not relevant to predict the evolution of the condensation heat transfer coefficient on the whole range of heat flux: at low heating powers, the correlations significantly overestimate $h_{\text {cond }}$ and correspond to an evolution of the heat transfer coefficient inverse to the one that is observed for the present device. For moderate and high heat fluxes, experimental data reach a steady value that is quantitatively well described by correlations close to the model from the Nusselt's theory, depending on the filling ratio and when considering the important uncertainty in $h_{\text {cond. }}$. As for the evaporation heat transfer coefficient, an accurate prediction should also assess the influence of $F R$. Two main reasons can be mentioned to explain the discrepancies between the experimental dataset and the correlations. First, as for $h_{\text {evap }}$, the predicted condensation heat transfer coefficient is fitted from data that do not take into account the conduction in the walls. Second, the hypothesis of a laminar liquid film is not valid on the whole range of experimental parameters due to confinement of the fluid: depending on the flow regime and filling ratio, the film of condensate returning to the evaporator section may indeed be disrupted by confined bubbles rising up to the condenserarea, leading to a more 
"chaotic" behavior in this section. The corresponding degradation in the thermal performance is therefore aggravated by very low filling ratios, low heat fluxes and low saturation temperatures that participate to flow regimes with large confined bubbles being propelled to the condenser region, as visible in Figure 13b.

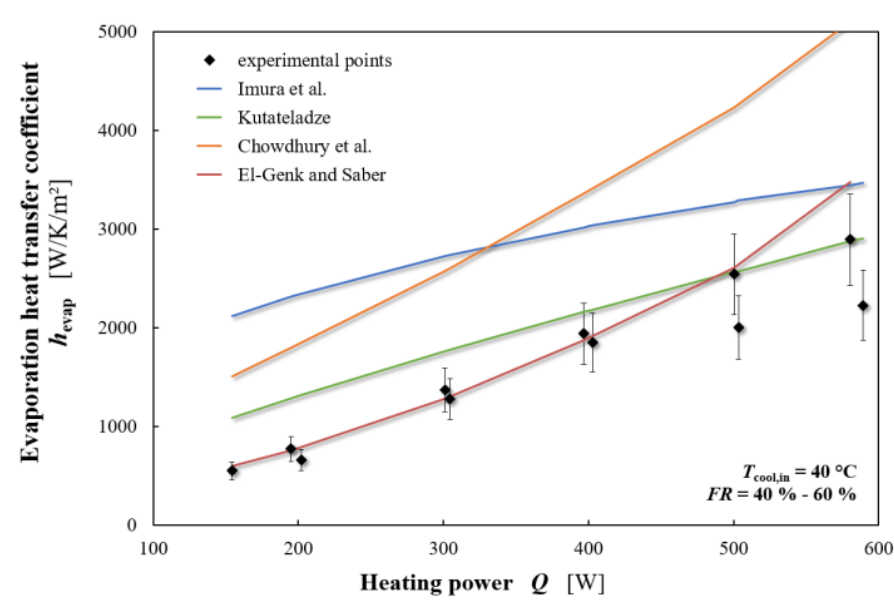

(a) evaporation heat transfer coefficient.

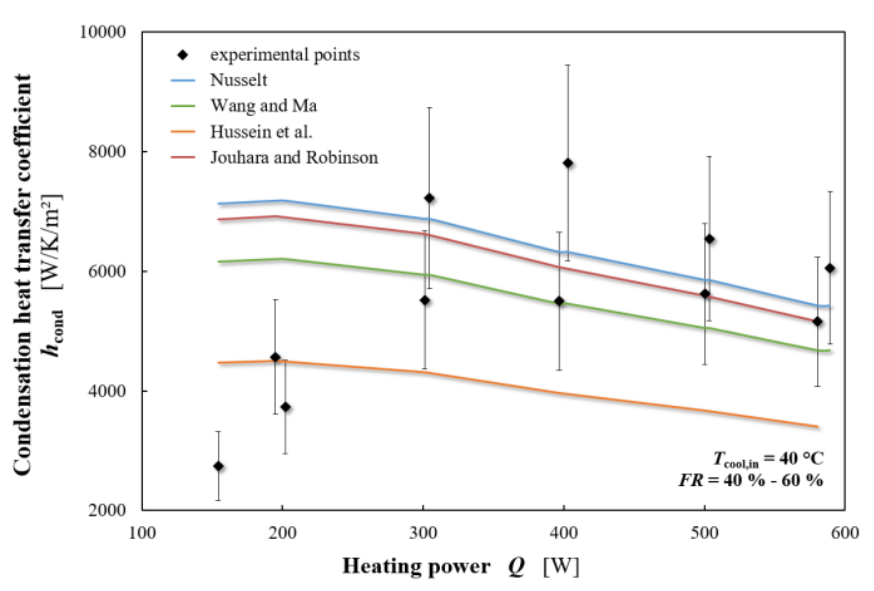

(b) condensation heat transfer coefficient.

Figure 13. Evaporation and condensation heat transfer coefficients according to heat load - measurements and correlations, for $40 \%$ and $60 \%$ filling ratios, $T_{\text {cool,in }}=40^{\circ} \mathrm{C}, \theta=90^{\circ}$.

Comparisons drawn about evaporation and condensation heat transfer coefficients between experimental data and selected correlations are summarized for all filling ratios in Figure 14 and Table 5. The specificity of the present device with the confinement of the fluid, along with the lack of correction for conduction effects and influence of filling ratio in the correlations, causes the large discrepancies observed in the figures.

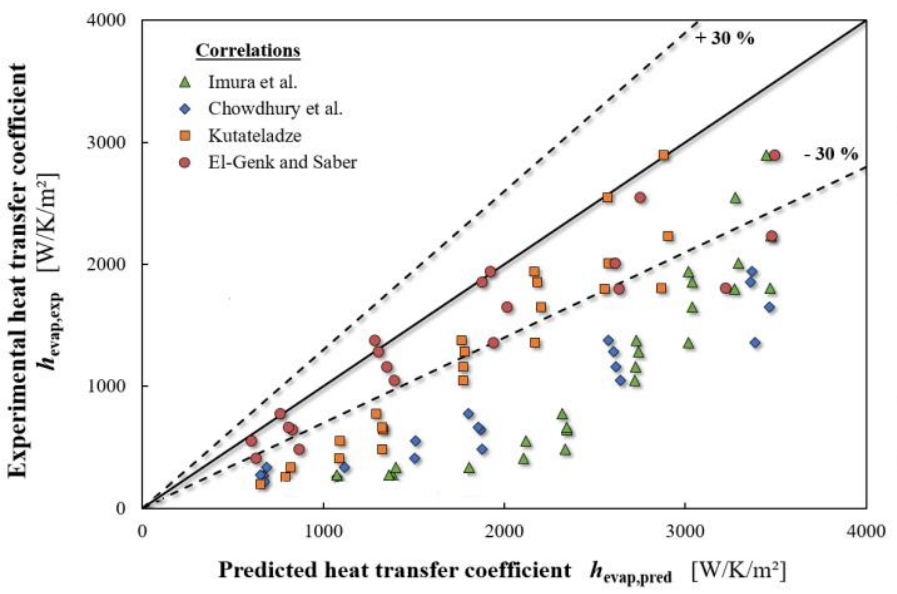

(a) evaporation heat transfer coefficient.

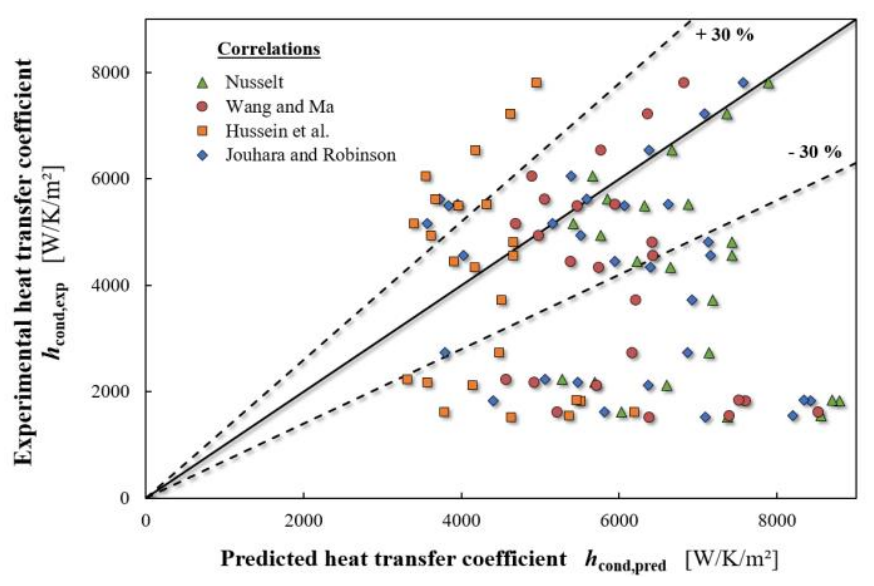

(b) condensation heat transfer coefficient.

Figure 14. Comparisons of heat transfer coefficients with empirical correlations $-T_{\text {cool, in }}=40^{\circ} \mathrm{C}, \theta=90^{\circ}$..

Table 5 provides indications for the Mean Absolute Error (MAE) and Mean Squared Error (MSE) in percentages of the prediction, and for the percentages of data within $30 \%$ and $50 \%$, respectively, for four filling ratios investigated during runs at $T_{\mathrm{cool}, \text { in }}=40{ }^{\circ} \mathrm{C}$, in vertical position. The highlighted correlation in each section gives the best prediction for the as sociated heat transfer coefficient in the global dataset. However, evolutions of $h$ at a specific filling ratio or on a restricted range of experimental parameters may be better described by another of the selected correlations: for example, the best agreement with experimental $h_{\text {cond }}$ in the globaldataset is obtained with the correlation from Hussein et al. (2001) according to Table 5 whereas the other three correlations provide more accurate predictions of the same quantity at $40 \%$ filling ratio and moderate to high heat fluxes, as visible in Figure 13b. In the case of $h_{\text {evap }}$, the El-Genk and Saber correlation provides the best description of heat transfer for both the global dataset and data at a given $F R$.

Improving the prediction of evaporation and condensation heat transfercoefficients in two-phase thermosyphons would therefore require to take into account both the conduction in the walls and the influence of the filling ratio. 


\begin{tabular}{|l|c|c|c|c|}
\hline Correlation & $\begin{array}{c}\text { MAE } \\
{[\%]}\end{array}$ & $\begin{array}{c}\text { MSE } \\
{[\%]}\end{array}$ & $\begin{array}{c}\text { data within 30 \% } \\
{[\%]}\end{array}$ & $\begin{array}{c}\text { data within 50 \% } \\
{[\%]}\end{array}$ \\
\hline Evaporation & \multicolumn{5}{|c|}{} \\
\hline Imura et al. & 52.4 & 102.1 & 10 & 50 \\
\hline Kutateladze & 32.1 & 43.1 & 50 & 85 \\
\hline Chowdhury et al. & 56.2 & 126.1 & 0 & 25 \\
\hline E-Genk and Saber & $\mathbf{1 8 . 3}$ & $\mathbf{3 8 . 2}$ & $\mathbf{7 0}$ & $\mathbf{1 0 0}$ \\
\hline Condensation & \multicolumn{5}{|l|}{} \\
\hline Nusselt & 32.1 & 61.0 & 50 & 70 \\
\hline Wang and Ma & 21.4 & 47.4 & 65 & 70 \\
\hline Hussein et al. & $\mathbf{8 . 2}$ & $\mathbf{4 0 . 1}$ & $\mathbf{7 0}$ & $\mathbf{9 0}$ \\
\hline Jouhara and Robinson & 29.2 & 56.8 & 50 & 70 \\
\hline
\end{tabular}

Table 5. Differences between empirical correlations and measurements for the present study, all filling ratios included, $T_{\text {cool, in }}=40^{\circ} \mathrm{C}, \theta=90^{\circ}$.

Influence of inclination

The influence of the inclination angle on the evaporation and condensation heat transfer coefficients can also be assessed. However, as previously mentioned and as shown in Figure 10b, the saturation temperature does not significantly change with the inclination angle; therefore, the evaporation and condensation heat transfer coefficients do not give any further information about the physical mechanisms causing this lack of sensitivity in the present study.

The evaporation heat transfer coefficient is anyway not really impacted by $\theta$, but the existence of the liquid film in the condenser region should cause the condensation heat transfer coefficient to change with the inclination angle, as several authors reported in empirical correlations, including Hussein et al. (2001) who developed a model for film condensation heat transfer inside a wickless heat pipe for a flat-plate solar collector:

$h_{\text {cond }}=h_{\text {Nusselt }}\left(\frac{L_{\text {cond }}}{D_{\text {i }}}\right)^{1 / 4(\cos \theta)^{0.358}}\left[0.997-0.334(\cos \theta)^{0.108}\right]$

where $h_{\text {Nusselt }}$ is calculated with the Nusselt theory as reported in Table 4 .

Figure 15 presents the experimental condensation heat transfer coefficient according to the inclination angle and the prediction provided by this correlation in the case of a flat thermosyphon for various filling ratios and a cooling temperatu re of $40{ }^{\circ} \mathrm{C}$. While a relative good quantitative agreement is observed for some of the filling ratios, the performance of the device studied here is not strongly affected by $\theta$, as expected by the model: the degradation of the heat transfer coefficient with the decrease of the angle is not as clear on the experimental trend, with relatively similar values between $45^{\circ}$ and $90^{\circ}$, and the changes in $h_{\text {cond }}$ are not significant compared to the uncertainty in this calculated quantity.

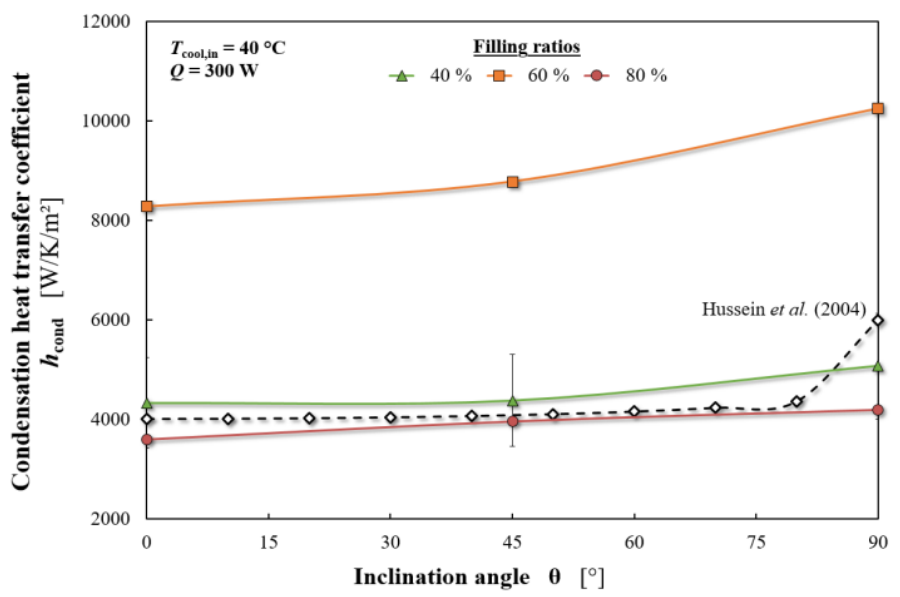

Figure 15. Evolution of the condensation heat transfer coefficient with the inclination angle. 


\section{CONCLUS IONS AND PERSPECTIVES}

Taking advantage of confined boiling phenomena in a flat thermosyphon allowed to build a novel two-phase heat spreader with interesting features for electronics cooling. Experiments including flow visualizations were performed to study both the underlying mechanisms and its thermal performance. They demonstrated that, despite complicated behavior characterization, this device can represent a viable solution for electronics cooling under challenging constraints such as in aeronautical applications. The flat confined thermosyphon exhibits:

- a suitable geometry for power modules and electronic components in addition to its compactness and simplicity;

- a high heat transfer capability (with a thermal resistance of $0.07 \mathrm{~K} / \mathrm{W}$ for a $10 \mathrm{~W} / \mathrm{cm}^{2}$ heat flux at a $40 \%$ filling ratio);

- a low sensitivity to changes in inclination with sufficient rewetted area in most configurations;

- a high degree of freedom for the heat sources location compared to a clas sical thermosyphon.

Experimental characterization of evaporation and condensation heat transfercoefficients were also performed by taking into account the conduction in the spreader to better understand underlying phase change processes. Comparisons were drawn with various literature correlations, highlighting reasonable agreement with existing datasets and underlining the need to take into account conduction effects and influence of filling ratio on heat transfer.

Further investigation for this study includes extensive characterization of flow patterns with the transparent spreader in various configurations in order to provide flow pattern maps, and additional experiments on thermal performance, at very high heat fluxes, for instance. Comparis ons of thermal performance with equivalent conductive spreader and classical nonconfined thermosyphons are also to be considered, as well as the as sessment of the influence of additional parameters and start-up modes such as frozen start-up, working fluid, inner thickness (relative to confinement) and more precise modelling and confrontation to models available in the literature.

\section{ACKNOWLEDGEMENTS}

This study was performed within the scope of the $\mathrm{I}^{2} \mathrm{MPECT}$ project with a funding of the European Commission $\mathrm{N}^{\circ} \mathrm{H} 2020$ MG-2014-636170.

\section{REFERENCES}

Bergles, A.E., Rohsenow, W.M., 1964. "The Determination of Forced-Convection Surface-Boiling Heat Transfer". Journal of Heat Transfer, Vol. 86(3), pp. 365-372.

Bonjour, J., Lallemand, M., 1998. "Flow patterns during boiling in a narrow space between two vertical surfaces". International Journal of Multiphase Flow, Vol. 24, pp. 947-960.

Chowdhury, F.M.D., Kaminaga, F., Goto, K., Matsumura, K., 1997. "Boiling heat transfer in a small diameter tube below atmospheric pressure on a natural circulation condition”. Journal of Japan Association for Heat Pipes, Vol. 16, pp. 14-26.

El-Genk, M.S., Saber, H.H., 1999. "Determination of operation envelopes for closed two-phase thermosyphons". International Journal of Heat and Masse Transfers, Vol. 42(5), pp. 889-903.

Faghri, A., 2014. "Heat pipes: review, opportunities and challenges". Frontiers in Heat Pipes 5, pp. 1-48.

Franco, A., Filippeshi, S., 2013. "Experimental analysis of Closed Loop Two Phase Thermosyphon (CLTPT) for energy systems". Experimental Thermal and Fluid Science, Vol. 51, pp. 302-311.

Imura, H., Sasaguchi, K., Kozai, H., 1983. “Critical heat flux in a closed two-phase thermosyphon”. International Joumal of Heat and Masse Transfers, Vol. 26(8), pp. 1181-1188.

Hu, M., Zheng, R., Pei, G., Wang, Y. Li, J., Ji, J., 2016. "Experimental study of the effect of inclination angle on the thermal performance of heat pipe photovoltaic/thermal (PV/T) systems with wickless heat pipe and wire-meshed heat pipe". Applied Thermal Engineering, Vol. 106, pp. 651-660.

Hussein, H.M.S., Mohamad, M.A., El-Asfouri, A.S., 2001. "Theoretical analysis of laminar-film condensation heat transfer inside inclined wickless heat pipes flat-plate solar collector". Renewable Energy, Vol. 23, pp. 525-535.

Jafari, D., Franco, A., Filippeschi, S., Di Marco, P., 2016. "Two-phase closed thermosyphons: A review of studies and solar applications". Renewable and Sustainable Energy Reviews, Vol. 53, pp. 575-593.

Jouhara, H., Robinson, A.J., 2010. "Experimental investigation of small diameter two-phase closed thermosyphons charged with water, FC-84, FC-77 and FC-3283". Applied Thermal Engineering, Vol. 30, pp. 201-211.

Li, J. and Lv, L., 2016. "Experimental studies on a novel thin flat heat pipe heat spreader". Applied Thermal Engineering, Vol. 93, pp. 139-146.

Lips, S., Lefèvre, F., Bonjour, J., 2009. “Thermal and hydrodynamic study of a flat plate heat pipe”. ExHFT-7, Poland.

Lips, S., Barrière, A., Narcy, M., Sartre, V., 2017. "Dispositif de diffusion thermique”. Patent FR 1750129. 
Liu, S., Li, J., Chen, Q., 2007. "Visualization of flow pattern in thermosyphon by ECT". Flow Measurement and Instrumentation, Vol. 18, pp. 216-222.

Noie, S.H., 2005. "Heat transfer characteristics of a two-phase closed thermosyphon". Applied Thermal Engineering, Vol. 25, pp. 495-506.

Noie, S.H., Sarmasti Emami, M.R., Khoshnoodi, M., 2007. "Effect of inclination angle and filling ratio on thermal performance of a two-phase closed thermosyphon under normal operating conditions". Heat Transfer Engineering, Vol. 28, No. 4, pp. 365-371.

Ong, K.S., Haider, M.D., Alalhi, E., 1999. "Experimental investigation on the hysteresis effect in vertical two-phase closed thermosyphons". Applied Thermal Engineering, Vol. 19, pp. 399-408.

Ong, K.S., Tong, W.L., Gan, J.S., Hisham, N., 2014. "Axial temperature distribution and performance of R410a and water filled thermosyphon at various fill ratios and inclinations". Frontiers in Heat Pipe, Vol. 5, No. 2.

Reay, D., McGlen, R., Kew, P., 2013. "Heat Pipes - Theory, Design and Applications". 6" Edition, published by Butterworth-Heinemann.

Rohsenow, W.M., Harnett, J.P., Ganic, E.N., 1985. "Handbook of heat transfer fundamentals". $2^{\text {nd }}$ Edition, New York, McGraw-Hill.

Rops, C.M., Lindken, R., Velthuis, J.F.M., Westerweel, J., 2009. "Enhanced heat transfer in confined pool boiling". International Journal of Heat and Fluid Flow, Vol. 30, pp. 751-760.

Smith, K., Byrne, G., Kempers, R., Robinson, A.J., 2016. "Electrohydrodynamic augmentation of a reflux thermosyphon". Experimental Thermal and Fluid Science, Vol. 79, pp. 175-186.

Sobhan, C.B., Rag, R.L., Peterson, G.P., 2007. "A review and comparative study of the investigation on micro heat pipes". International Journal of Energy Research, Vol. 31, No. 6-7, pp. 664-688.

Terdtoon, P., Waowaew, N., Tantakom, P., 1999. "Internal flow patterns of an inclined closed two-phase thermosyphon at critical state: case study II, effect of Bond number", Experimental Heat Transfer, Vol. 12, pp. 359-373.

Tong, L., Chen, J., Cao, X., Yang, S., Liao, S., Deng, J., Zeng, W., 2015. "Visualization experiments on the geyser boiling-induced instability in vertical circular tube at low-pressures". Annals of Nuclear Energy, Vol. 77, pp. 487-497.

Wang, J.C.Y, Ma, Y., 1991. "Condensation heat transfer inside vertical and inclined thermosyphons". Journal of Heat Transfer, Vol. 113, pp. 777-780.

Zhang, G., Liu, Z., Wang, C., 2013. “An experimental study of boiling and condensation co-existing phase change heat transfer in small confined space". International Journal of Heat and Mass Transfer, Vol. 64, pp. 1082-1090.

Zhang, M., Lai, Y., Pei, W., Jin, L., 2014. "Effect of inclination angle on the heat transfer performance of a two-phase closed thermosyphon under low-temperature conditions". Journal of Cold Regions Engineering, Vol. 28, No. 4. 